\title{
Implicações didáticas de história da ciência no ensino de Física: uma revisão de literatura através da análise textual discursiva+*
}

\author{
Edmundo Rodrigues Junior ${ }^{1}$ \\ Instituto Federal do Espírito Santo \\ Vitória - ES \\ Fernando J. Luna ${ }^{2}$ \\ Marília Paixão Linhares ${ }^{3}$ \\ Cassiana Barreto Hygino ${ }^{4}$ \\ Universidade Estadual Norte Fluminense \\ Campos dos Goytacazes - RJ
}

\section{Resumo}

Este trabalho mostra uma revisão de literatura sobre as implicações didáticas de história da ciência no ensino de física no período compreendido entre 2010 a 2014. A técnica utilizada para analisar os dados foi a análise textual discursiva (ATD) com as categorias definidas a priori. Essas categorias contemplam distintas estratégias didáticas para o ensino de história da ciência em aulas de física tais como: o uso das fontes primárias ou originais, dos estudos de caso histórico, das atividades de dramatização, dos experimentos históricos, das biografias elou autobiografias dos cientistas e, da análise de conteúdos de história da ciência presentes nos livros didáticos. $O$ resultado mostrou que 36 artigos, dos 1659 disponibilizados nos periódicos consultados, utilizam essas estratégias de ensino. A etapa interpretativa dos resultados consistiu na produção de seis metatextos

\footnotetext{
${ }^{+}$Didactic implications of the history of science in physics education: a literature review through discursive textual analysis

* Recebido: setembro de 2014. Aceito: outubro de 2015.

${ }^{1}$ E-mail: edmundo.cruzeiro@gmail.com

${ }^{2}$ E-mail: fernando@uenf.br

${ }^{3}$ E-mail: mariliapaixaolinhares@gmail.com

${ }^{4}$ E-mail: cacahygino@yahoo.com.br
} 
onde foram identificados dois objetivos de aprendizagem: o primeiro relacionado aos conceitos físicos e o segundo em aspectos relacionados ao entendimento da natureza da ciência. Identificamos também, no nosso corpus, os instrumentos de avaliação utilizados pelos autores para mensurar o conhecimento dos alunos.

Palavras-chave: História da Ciência; Ensino de física; Análise textual discursiva.

\begin{abstract}
This work presents a literature review of the educational implications of the history of science in the teaching of Physics in the period 2010 to 2014. The technique used to analyze the data was the discursive textual analysis with the categories defined a priori. These categories include different teaching strategies for the teaching of history of science in Physics classes such as the use of primary or original sources, historical case studies, science through drama activities, historical experiments, biographies and lor autobiographies of scientists and the content analysis of the history of science present in textbooks. The result showed that 36 articles of 1659 available in journals use these teaching strategies. The results of the interpretative step consisted in the production of six metatexts in which two learning objectives were identified: the first one is related to physical concepts and the second one in aspects related to understanding the Nature of Science. The evaluation tools used by the authors to assess the students' knowledge were identified in our corpus too.
\end{abstract}

Keywords: History of Science; Physics education; Discursive textual analysis.

\title{
I. Introdução
}

A utilização da história da ciência não é assunto recente. No final do século XIX professores ingleses já inseriam a história da ciência em suas aulas como uma maneira de motivar os discentes nas aulas de ciências (SHERRATT, 1982, apud SEQUEIRA; LEITE, 1988). O debate para a anexação da história da ciência nos currículos de ciências foi amplamente discutido em todo o século XX (DUARTE, 2004). Inúmeros projetos e documentos internacionais do século anterior ratificam a importância da interface entre a história da ciência e o ensino de ciências. No artigo denominado "Introdução: a importância da história da ciência na educação científica", Prestes e Caldeira (2009) elencam os principais documentos oficiais de vários países 
que orientam a incorporação da história da ciência nos seus currículos de ciências com o objetivo de promover a alfabetização científica ${ }^{5}$. O National Curriculum Council (NCC), do Reino Unido; o National Research Council (NRC) e o American Association for the Advanced of Science (AAAS), ambos desenvolvidos nos Estados Unidos são exemplos desses documentos.

No Brasil as orientações para o ensino de história das ciências aparecem implicitamente nas Diretrizes Curriculares Nacionais para a Formação de Professores da Educação Básica, nos Parâmetros Curriculares Nacionais $\left(\mathrm{PCN}\right.$ e $\left.\mathrm{PCN}^{+}\right)$e nos Programas Nacionais do Livro Didático (PNLD).

As orientações das Diretrizes para professores sugerem que o professor do ensino básico reúna condições para superar a fragmentação dos conteúdos (BRASIL, 2001, p.28). Essa fragmentação pode ser reduzida através da associação entre os conteúdos de física aos seus aspectos sociais, históricos, culturais e econômicos que lhe deram origem.

Os PCN para o Ensino Médio atribuem alguns itens relacionados à história da Ciência, que compõem a competência "contextualização sociocultural". Tais itens têm como objetivos: a) reconhecer o sentido histórico da ciência e da tecnologia, percebendo seu papel na vida humana em diferentes épocas e na capacidade humana de transformar o meio e, b) compreender as ciências como construções humanas, entendendo como elas se desenvolveram por acumulação, continuidade ou ruptura de paradigmas, relacionando o desenvolvimento científico com a transformação da sociedade. (BRASIL, 2000, parte III, p.13)

Os $\mathrm{PCN}^{+}$para o Ensino Médio ressaltam que o ensino de história da ciência possibilita ao aluno "questionar e compreender melhor processos sociais, econômicos e culturais passados e contemporâneos" (BRASIL, 2002, p.18).

A abordagem da história da ciência no ensino também encontra respaldo nos PCN para o Ensino Fundamental porque busca compreender a Ciência como um processo de produção de conhecimento e uma atividade humana, histórica, associada a aspectos de ordem social, econômica, política e cultural (BRASIL, 1998, p.71)

Percebe-se através dos parâmetros curriculares nacionais a importância atribuída à história da ciência como eixo norteador para relacionar os conhecimentos científicos aos conhecimentos sociais, econômicos e culturais. Esses debates interdisciplinares também são preocupações de Hessen e Merton (apud Borges, 1996) (influência sócio-política e econômica) e Feyerabend e Morin, (apud Borges, 1996) (sociológica e cultural).

A história da ciência também está presente no Programa Nacional do Livro Didático (PNLD) de Física para o Ensino Médio. Esse documento orienta a articulação entre os conhecimentos científicos e os aspectos históricos, tecnológicos, sociais e econômicos, com o objetivo de formar o aluno cidadão (PNLD-FÍSICA, 2012, p.8).

\footnotetext{
5 Segundo Sasseron et al (2013) existem três eixos estruturantes da alfabetização científica: a compreensão básica de termos conhecimentos e conceitos científicos fundamentais; a compreensão da natureza das ciências e dos fatores éticos e políticos que circundam sua prática e, o entendimento das relações existentes entre ciência, tecnologia, sociedade e meio ambiente.
} 
Já O PNLD- EJA escrito para a educação de jovens e adultos orienta que os conteúdos escolares devem evidenciar a historicidade do conhecimento científico (PNLD-EJA, 2011, p.233).

Apesar da importância atribuída à história da ciência nos documentos oficiais, os conteúdos da disciplina física ensinados nas escolas ainda são muito fragmentados e explicados através de fórmulas matemáticas desconexas (BORGES, 2006; HYGINO et al, 2012). Geralmente, os professores não apresentam aos alunos a origem dessas expressões matemáticas e o contexto social, político, econômico e cultural em que foram produzidas, o que dificulta a construção de uma visão de mundo mais integradora. A falta de formação específica, a carência de materiais didáticos de história da ciência e o tempo excessivo de aulas podem ser indicadores sobre a razão desse ensino fragmentado.

Com o objetivo de oferecer aos professores de física subsídios metodológicos para melhorar a qualidade das suas aulas, fomos motivados a percorrer os caminhos trilhados na literatura recente sobre as implicações didáticas da história da ciência no ensino de física. Este trabalho, portanto, é um artigo de revisão de literatura que pode ser um embrião para motivar os professores de física a utilizarem a história da ciência, tornando suas aulas mais dinâmicas, criativas e humanas.

\section{Fundamentação teórica}

Muitos autores tais como Matthews (1995) e Allchin (1999) apontam a história da ciência como alternativa para favorecer um ensino contextualizado, crítico, amplo e interdisciplinar. Assim, a história da ciência é importante para o ensino porque: a) promove a humanização da ciência que consiste em associar o desenvolvimento da ciência às questões éticas, culturais, sociais, políticas e econômicas segundo o contexto de cada época e lugar. Essa associação motiva aqueles discentes que não se interessam pelas estratégias de ensino "tradicionais" (MATTHEWS, 1995; FERREIRA; MARTINS, 2008; MCCOMAS, 2013, p. 429), b) contribui para o tratamento interdisciplinar dos conteúdos (MATTHEWS, 1995; FERREIRA; MARTINS, 2008; MCCOMAS, 2013, p. 429; ZANETIC, 1989), c) mostra a importância intrínseca da história ciência como "herança cultural da humanidade" (FERREIRA; MARTINS, 2008), d) auxilia a compreensão dos conteúdos científicos (MATTHEWS, 1995; FERREIRA; MARTINS, 2008; MCCOMAS, 2013, p. 429; PEDUZZI, 2011, p. 15), e) permite que o professor entenda as concepções alternativas dos estudantes (FERREIRA; MARTINS, 2008), f) contribui para evitar as visões deformadas da construção do conhecimento científico (FERREIRA; MARTINS, 2008; GIL PÉREZ et al., 2001), g) fundamenta teoricamente a didática de ciências (FERREIRA; MARTINS, 2008).

Após a descrição e a explicação dos argumentos favoráveis ao uso da história da ciência no ensino, poderá surgir a seguinte pergunta: como conduzir o aluno a compreender a ciência como construção humana e reconhecer a importância da história da ciência para sua alfabetização científica? 
Uma maneira de auxiliar o professor a lecionar história da ciência consiste na aplicação das estratégias de ensino de história da ciência na educação científica, descritas em McComas (2013). Essas abordagens envolvem o uso de fontes originais, estudos de caso, dramatização, experimentos históricos, biografia e autobiografias de cientistas, a história da ciência presentes nos livros didáticos. McComas (2013) propôs essa classificação com dois objetivos distintos: o primeiro foi para explicitar ao leitor o grande número de abordagem e exemplos da história da ciência que pode ser usada no ensino de ciências. O segundo teve como propósito alertar o leitor sobre as aplicações distintas dessas estratégias na educação científica e revelar que os esforços diversos de professores e estudantes para a aplicação dessas estratégias, não produzem necessariamente o mesmo impacto no aprendizado e na afetividade do aluno.

As fontes originais representam a abordagem da história da ciência na qual os alunos estudam conceitos vigentes da época a partir dos escritos dos cientistas e então participam de discussões sobre o que eles estudaram (MCCOMAS, 2013). Ainda segundo esse autor a interação com trabalhos originais pode ser classificada como: a) trabalhos originais completos (podem incluir comentários originais) e trabalhos originais resumidos (podem incluir comentários adicionais).

$\mathrm{O}$ estudo de caso histórico se caracteriza por princípios gerais que possibilitem o resgate do contexto em que se deu algum problema marcante na ciência (STINNER, 2003). Esse contexto histórico revela os motivos pelos quais certos aspectos do desenvolvimento da ciência e da tecnologia foram construídos. Estes aspectos incluem as questões pessoais do cientista bem como seu envolvimento com questões éticas, sociológicas, políticas, econômicas e religiosas.

A dramatização é uma estratégia de ensino nas quais os alunos interpretam personagens históricos da ciência com o objetivo de agir, debater ou responder como se fossem essas pessoas (MCCOMAS, 2013, p. 438). Uma encenação dos debates entre Simplício (defensor das ideias de Aristóteles) e Salviatti (defensor das ideias de Galileu) poderia ser um bom exemplo de dramaturgia.

Os Experimentos históricos consistem na reprodução de experimentos e outras abordagens práticas para o engajamento com alguns aspectos históricos da ciência (MCCOMAS, 2013, p. 440).

A biografia e autobiografia é o relato da vida e/ou da pesquisa dos cientistas escritas por eles mesmos (autobiografia) ou por outra pessoa (biografia). MCcomas (2013) relata alguns exemplos de autobiografias de Charles Darwin, James Watson e Richard Feyman; e biografias, tais como: Galileo's Daughter, Einstein e Isaac Newton. MCcomas cita alguns produtos de mídia que tem sido produzido com fins educacionais como, por exemplo, a série MindWorks contendo oito vídeos envolvendo os trabalhos de Galileo, na cinemática; de Duchaltelet e Voltaire, na dinâmica; do Conde Rumford, na termodinâmica; de Curie and Huggins sobre átomos e matéria; entre outros.

A História da ciência em livros didáticos como estratégia de ensino, procura analisar 
os conteúdos de história da ciência veiculados nos livros didáticos, com o objetivo de auxiliar o professor a identificar os conceitos de história da ciência e possíveis visões deformadas da natureza da ciência presentes nesses livros didáticos. Quando os cientistas são mencionados nos livros didáticos "[...] suas contribuições estão limitadas a poucas frases, talvez uma figura, e às datas de nascimento e morte" (MCCOMAS, 2013, p. 439).

É importante observar que essas estratégias não constituem divisões estanques, elas se complementam umas com outras. Por exemplo, pode-se utilizar na $2^{\mathrm{a}}$ fase do estudo de caso experimentos históricos, fontes originais, dramatização ou até mesmo conteúdos de história da ciência presentes em livros didáticos.

Após a descrição e explicação das maneiras de aproximação entre os trabalhos dos historiadores da ciência e dos professores e as estratégias de ensino para a explicação da história da ciência na educação científica, faz-se necessário apresentar um levantamento de cunho bibliográfico sobre as principais implicações didáticas da história da ciência no ensino de física com o objetivo de oferecer aos professores de física algumas estratégias para melhorar a qualidade das suas aulas.

\section{Metodologia}

\section{III.1 A seleção dos artigos}

Para uma melhor compreensão da história da ciência no ensino de ciências, especificamente no ensino de física, delineamos alguns caminhos já trilhados na literatura sobre o tema nos seguintes periódicos: Caderno Brasileiro de Ensino de Física (CBEF), Revista Brasileira de Ensino de Física (RBEF), Revista Ciência e Educação, Revista Eletrônica Ensenanza de las ciências (REEC), Revista Experiências em ensino de ciências (EENCI), Revista investigações em Ensino de Ciências (IENCI), Revista Science \& Education (S\&E). A consulta aos periódicos supracitados foi realizada no período compreendido entre janeiro de 2010 e maio de 2014. O critério para escolha das revistas baseou-se na classificação igual ou superior ao conceito B2 (ou seja, revistas avaliadas com os conceitos A1, A2, B1 e B2) do qualis capes (comitês de ensino ou interdisciplinar) e, que continham trabalhos relacionados à história da física no ensino e, ainda com disponibilidade na plataforma virtual CAFE (Comunidade Acadêmica Federada).

\section{III.2 A técnica para analisar os artigos}

Para analisar os artigos utilizamos a técnica Análise Textual Discursiva (ATD). A ATD propõe-se a "descrever e interpretar alguns dos sentidos que a leitura de um conjunto de textos pode suscitar" (MORAES; GALIAZZI, 2011, p. 14)

A ATD é constituída por três etapas que ocorrem em um processo cíclico:

a) desmontagem dos textos ou unitarização: "implica examinar os textos em seus detalhes, fragmentando-os no sentido de atingir unidades constituintes, enunciados referentes aos fenômenos estudados" (MORAES; GALIAZZI, 2011, p. 11), tendo o cuidado de se manter o 
contexto de onde o fragmento foi retirado. Segundo Hygino et al. (2013), nesta etapa deve-se dar atenção aos detalhes e nas partes dos componentes dos textos, uma fase de decomposição necessária a toda análise. É o próprio pesquisador quem decide em que medida fragmentará seus textos. Dessa desconstrução dos textos surgem as unidades de análise, também chamadas de unidades de significado ou sentido (MORAES; GALIAZZI, 2011, p. 18). Essas unidades podem ser empíricas, coletadas para a pesquisa, e teóricas, provenientes dos autores utilizados para embasar o tema pesquisado (HYGINO et al., 2013, p. 53). No nosso caso as unidades empíricas correspondem à transcrição literal das frases extraídas dos artigos dessa revisão e as unidades teóricas correspondem a outros autores selecionados para embasar essas unidades empíricas. Cada unidade de análise deve receber um título, que represente a ideia principal da unidade e código a fim de identificar seu texto de origem bem como sua localização dentro desse texto.

b) Estabelecimento de relações ou categorização: consiste na construção de relações entre as unidades de análise, tanto as empíricas, quanto as teóricas. Fazemos isso num processo recursivo de leitura e comparação entre as mesmas, resultando em conjuntos que apresentam elementos semelhantes, daí surgem às categorias. (HYGINO, et al., 2013, p. 53).

Podemos afirmar que a categorização é um processo de criação, ordenamento, organização e síntese (HYGINO et al., 2013, p. 53). Constitui, ao mesmo tempo, processo de construção de compreensão de fenômenos investigados, aliada à comunicação dessa compreensão por meio de uma estrutura de categorias (MORAES; GALIAZZI, 2011, p. 78).

As categorias de análise da ATD podem ser definidas a priori ou pode surgir das leituras (categoria emergente), ou ainda, podem ser mistas. Nesse trabalho, optamos pela categoria a priori "[...] quando a opção é trabalhar com categorias a priori, o pesquisador deriva suas categorias de seus pressupostos teóricos [...]" (MORAES; GALIAZZI 2011, p. 117). Assim, a escolha pelas categorias a priori fundamentou-se nas estratégias de ensino de história da ciência, publicadas em McComas (2013). As categorias escolhidas a priori foram: fontes primárias, estudo de caso histórico, dramatização, experimentos históricos, biografia e autobiografia e livros didáticos.

c) Comunicação ou produção de metatextos: nessa etapa, percebe-se uma nova compreensão do todo, possibilitada pelo intenso envolvimento nas etapas anteriores. O objetivo dessa etapa é elaborar um texto descritivo e interpretativo, o qual se denomina metatexto, a partir das categorias. (HYGINO, et al., 2013, p. 53). Segundo Moraes e Galliazzi (2011) saber empregar as categorias construídas na análise para organizar a produção escrita é uma forma de atingir descrições e interpretações válidas dos fenômenos investigados. Afirmam ainda que "a qualidade dos textos resultantes das análises não depende apenas de sua validade e confiabilidade, mas é, também, consequência do fato de o pesquisador assumir-se autor de seus argumentos" (MORAES; GALIAZZI, 2011, p. 32). O esquema a seguir resume as etapas da ATD utilizada nesse trabalho. 


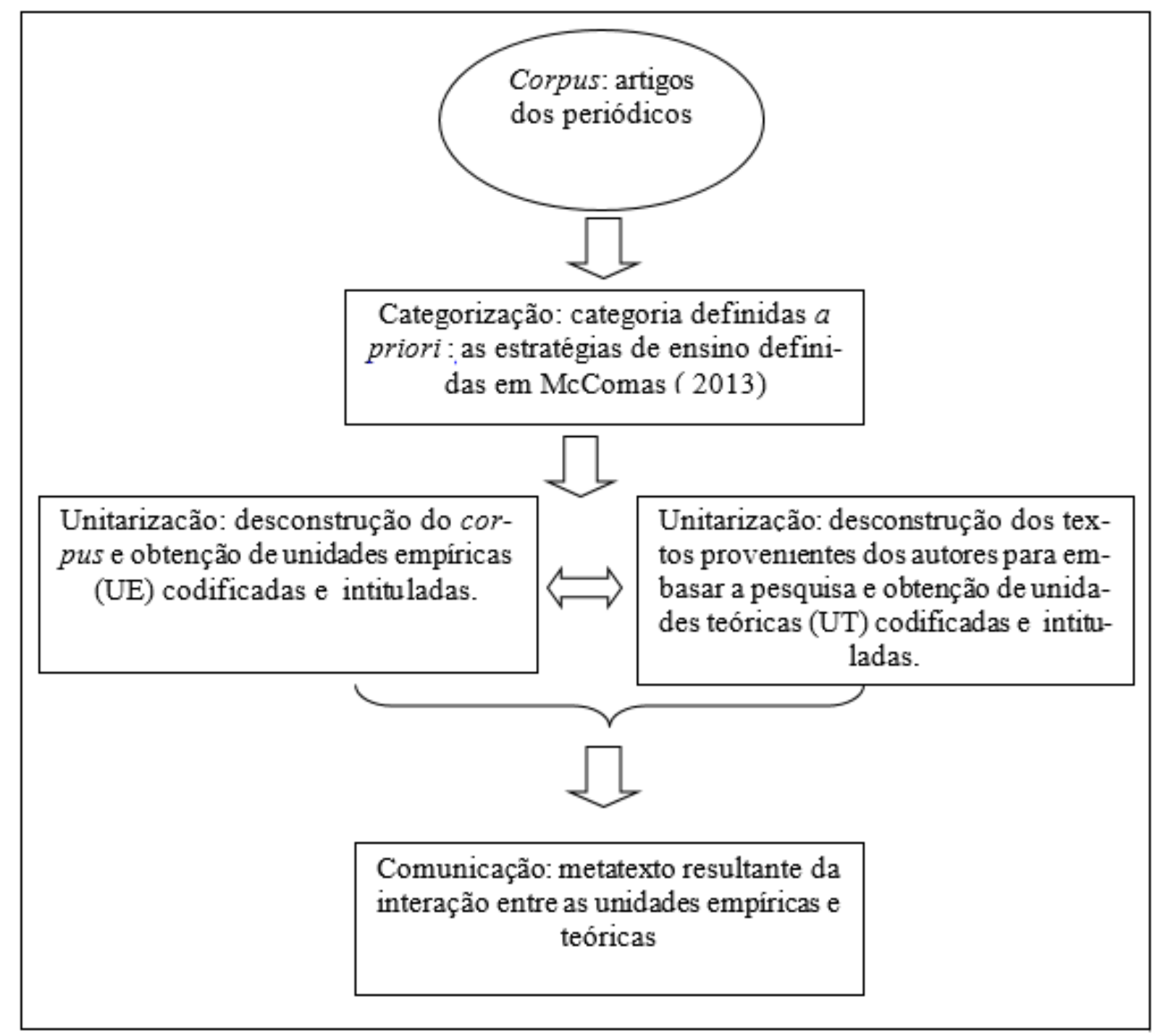

Fig. 1 - Síntese das etapas da ATD utilizada na revisão de literatura.

\section{Resultados}

Nossa revisão indicou um total de 1659 artigos distribuídos nos periódicos supracitados entre janeiro de 2010 e julho de 2014. Deste montante, 36 artigos (2,2\%) têm como propósito as implicações didáticas da história da ciência no ensino de física. Inicialmente analisamos os resumos e a conclusão dos artigos selecionados. Quando necessário, recorremos a outras partes do texto. A análise dos artigos consistiu em duas etapas: uma descritiva, que permitiu identificar a quantidade de artigos por periódico, o público alvo em relação aos segmentos de ensino e as estratégias de ensino de história da ciência. A outra etapa foi interpretativa, que consistiu na seleção das unidades empíricas e teóricas e a produção dos metatextos proveniente da interação entre essas unidades. Constatamos que os artigos apresentam como objetivos a aprendizagem da natureza da ciência e dos conceitos físicos. 


\section{IV.1 Etapa descritiva}

\section{IV.1.1 Número de artigos por periódicos}

A tabela 1 mostra na segunda coluna, a quantidade de artigos total por periódico encontrado na nossa revisão. Na terceira coluna encontra-se o número de artigos com implicações didáticas de história da ciência no ensino de física e, na quarta coluna, a relação percentual entre eles no período entre janeiro de 2010 e julho de 2014.

Tabela 1- Número de artigos disponibilizados nos periódicos, artigos com implicações didáticas de história da ciência no ensino de física e a relação percentual entre eles no período entre janeiro de 2010 e julho de 2014.

\begin{tabular}{c|c|c|c}
\hline Periódicos & $\begin{array}{l}\text { Total de artigos dis- } \\
\text { ponibilizados entre } \\
\text { jan. 2010 e jul. de } \\
2014\end{array}$ & $\begin{array}{l}\text { Total de artigos encon- } \\
\text { trados com implicações } \\
\text { didáticas de história da } \\
\text { ciência no ensino de fí- } \\
\text { sica entre jan. 2010 e jul. } \\
\text { de 2014 }\end{array}$ & $\begin{array}{l}\text { Porcentagem dos artigos com } \\
\text { implicações de história da ci- } \\
\text { encia no ensino de física em } \\
\text { relação ao número total de ar- } \\
\text { tigos disponibilizados nos pe- } \\
\text { riódicos }\end{array}$ \\
\hline CBEF & 156 & 9 & $5,8 \%$ \\
RBEF & 370 & 8 & $2,2 \%$ \\
Ciência \& & 255 & 3 & $1,2 \%$ \\
Educação & 133 & 2 & $1,5 \%$ \\
REEC & 135 & 3 & $2,2 \%$ \\
EENCI & 124 & 1 & $0,8 \%$ \\
IENCI & 486 & 36 & $2,1 \%$ \\
S\&E & 1659 & 10 & $2,2 \%$ \\
Total & & 2 & \\
\hline
\end{tabular}

Entre janeiro de 2010 e julho de 2014, verificamos que em três periódicos consultados (RBEF, EENCI e S\&E) existem praticamente a mesma porcentagem de artigos com implicações didáticas de história da ciência no ensino de física em relação ao número total de artigos do periódico $(2,2 \%)$. A revista IENCI detém o menor percentual $(0,8 \%)$ dos artigos que utilizam estratégias didáticas de história da ciência no ensino de física. A revista CBEF é a que possui maior porcentagem de artigos destinados ao ensino de história da ciência nas aulas de física (5,8\%). Percebe-se assim que os valores percentuais oscilam entre $0,8 \%$ e $5,8 \%$. Seria precipitado dizer, no entanto, que existe uma demanda de publicações que envolvem a história da ciência no ensino, porque esses periódicos não são específicos de história da ciência, aceitando publicações de outras áreas da educação em ciências tais como ambientes virtuais no ensino de ciências, o uso de experimentos no ensino de ciências, aplicações do enfoque CTS 
(ciência, tecnologia e sociedade) na sala de aula, dentre outras. Uma comparação entre as implicações didáticas da história da ciência no ensino e essas outras áreas da educação em ciências poderá ser feito em um trabalho ulterior.

Buscando descobrir o comportamento numérico anual dos artigos relacionados ao uso da história da ciência no ensino de física, construímos o gráfico abaixo.

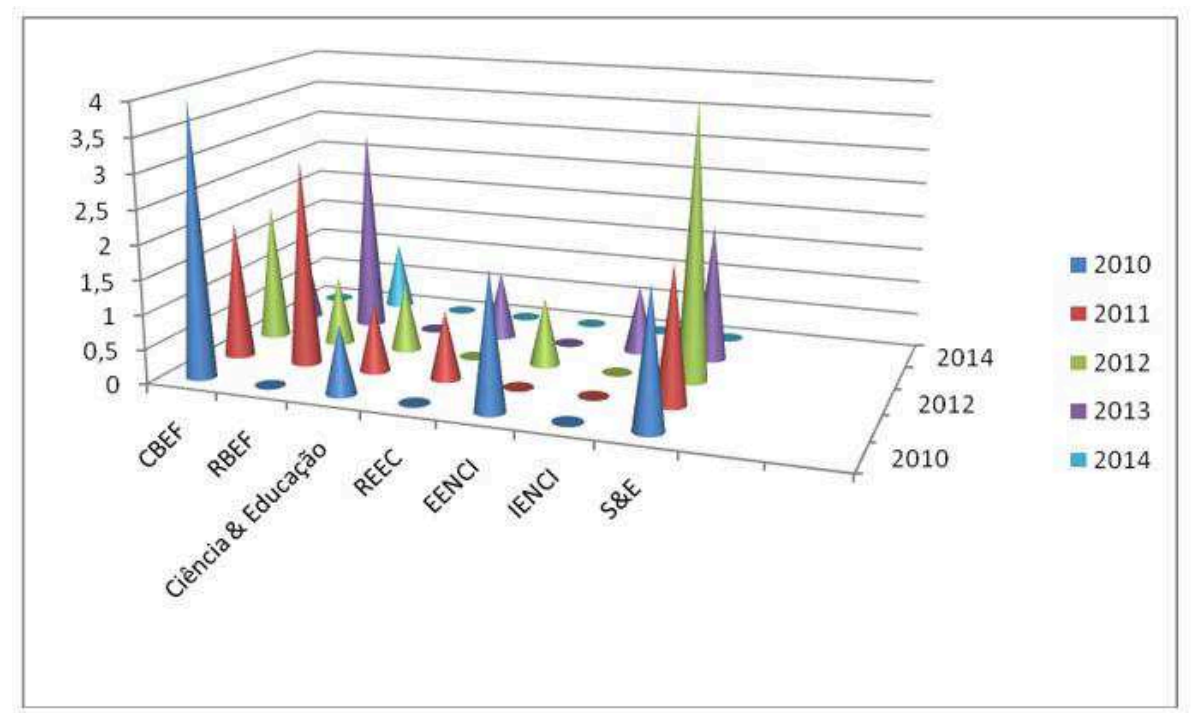

Gráfico 1 - Distribuição anual dos artigos nos periódicos.

De acordo com o gráfico1, verificamos que os anos de 2010 a 2013 a soma anual dos artigos com implicações didáticas de história da ciência no ensino de física permaneceu praticamente constante (nove artigos em 2010, nove artigos em 2011, nove artigos em 2012 e 8 artigos em 2013). No primeiro semestre de 2014 (até julho de 2014) encontramos nos periódicos da nossa revisão um artigo sobre história da ciência no ensino de física (pertencente à revista $\mathrm{RBEF}$ ). Isso não sinaliza uma diminuição dos artigos da área porque essa pesquisa não contemplou artigos do $2^{\circ}$ semestre do ano de 2014.

A revista IENCI publicou no período analisado exatamente um trabalho de história da ciência no ensino de física.

\section{IV.1.2 O público alvo por segmento de ensino}

A tabela 2 ilustra uma síntese quantitativa da distribuição dos artigos em relação ao público alvo no ensino presencial (superior, médio, fundamental, e na educação profissional de jovens e adultos - PROEJA: ensino médio). 
Tabela 2 - Artigos encontrados em periódicos em relação ao público contemplados com a abordagem da história da ciência por segmento de ensino.

\begin{tabular}{|c|c|c|c|c|c|}
\hline \multirow[b]{2}{*}{ Periódicos } & \multicolumn{4}{|c|}{ Alunos } & \multirow[b]{2}{*}{ Total } \\
\hline & $\begin{array}{l}\text { Ensino } \\
\text { Supe- } \\
\text { rior }\end{array}$ & $\begin{array}{l}\text { En- } \\
\text { sino } \\
\text { Médio }\end{array}$ & $\begin{array}{l}\text { Ensino Fun- } \\
\text { damental }\end{array}$ & $\begin{array}{l}\text { Educação de jovens e } \\
\text { adultos em formação } \\
\text { profissional (PROEJA) }\end{array}$ & \\
\hline CBEF & 5 & 7 & 0 & 0 & 12 \\
\hline RBEF & 6 & 6 & 0 & 0 & 12 \\
\hline $\begin{array}{c}\text { Ciência \& Educa- } \\
\text { ção }\end{array}$ & 2 & 2 & 0 & 0 & 4 \\
\hline REEC & 0 & 1 & 0 & 1 & 2 \\
\hline EENCI & 1 & 1 & 0 & 1 & 3 \\
\hline IENCI & 1 & 1 & 0 & 0 & 2 \\
\hline $\mathrm{S} \& \mathrm{E}$ & 6 & 4 & 2 & 0 & 12 \\
\hline Total & 21 & 22 & 2 & 2 & 47 \\
\hline
\end{tabular}

De acordo com os dados transcritos na tabela 1 observamos uma diferença entre o número total de artigos encontrados nos periódicos (36) e, a distribuição total desses trabalhos em relação aos públicos (47). Isto acontece porque em dez artigos revisados encontramos trabalhos simultâneos com: ensino médio e superior (CORDEIRO; PEDUZZI, 2010, 2011, 2013; GOMES, 2012; KRAPAS, 2011; JUNIOR et al., 2012; NOBREGA et al., 2013; OLIVEIRA et al., 2013; RAMIREZ et al., 2010) e ensino fundamental, médio e superior (BLOWN; BRYCE, 2013).

Observamos a existência de onze artigos que utilizam a história da ciência somente do público alvo do ensino superior: Brenni, 2012; Coelho, 2010; Ducheyne, 2012; Gauld, 2010; Gomes; Pietrocola, 2011; Klassen et al., 2012; Neto; Junior, 2013; Penereiro, 2010; Silveira et al., 2010; Teixeira et al., 2010; Zanotello, 2011.

Encontramos doze artigos que utilizam a história da ciência somente com alunos do ensino médio: Braga et al., 2012; Briccia; Carvalho, 2011; Francisquini et al., 2014; Guerra et al., 2013; Medina; Braga, 2010; Paraskevopoulou; Koloiopoulous, 2011; Pena; Teixeira, 2013; Rinaldi; Guerra, 2011; Rodrigues et al., 2012; Silva; Martins, 2010; Silva et al., 2011; Urias; Assis, 2012.

Achamos um artigo que tem como público alvo somente os alunos do ensino fundamental: Piliouras et al., 2011.

Encontramos dois artigos que tem como público alvo a Educação de Jovens e Adultos em formação profissional (PROEJA): Hygino et al., 2012, 2013. 


\section{IV.1.3 As estratégias de ensino}

A tabela 3 mostra um resumo da quantidade de artigos encontrados nessa revisão em relação as estratégias de ensino.

Tabela 3 - Estratégias de ensino para a utilização de história da ciência no ensino de física.

\begin{tabular}{|c|c|c|c|c|c|c|c|}
\hline \multirow{2}{*}{$\begin{array}{l}\text { Periódi- } \\
\text { cos }\end{array}$} & \multicolumn{6}{|c|}{ Estratégias de Ensino } & \\
\hline & $\begin{array}{l}\text { Fon- } \\
\text { tes } \\
\text { origi- } \\
\text { nais }\end{array}$ & $\begin{array}{l}\text { Estudo } \\
\text { de caso } \\
\text { histórico }\end{array}$ & $\begin{array}{l}\text { Dramati- } \\
\text { zação }\end{array}$ & $\begin{array}{l}\text { Experi- } \\
\text { mentos } \\
\text { históricos }\end{array}$ & $\begin{array}{l}\text { Biografia e/ou } \\
\text { autobiografia } \\
\text { dos cientistas }\end{array}$ & $\begin{array}{l}\text { Livros } \\
\text { didáti- } \\
\text { cos. }\end{array}$ & Total \\
\hline CBEF & 2 & 0 & 1 & 1 & 1 & 4 & 9 \\
\hline $\begin{array}{c}\text { RBEF } \\
\text { Ciência }\end{array}$ & 1 & 0 & 0 & 2 & 1 & 4 & 8 \\
\hline $\begin{array}{l}\text { \& Edu- } \\
\text { cação }\end{array}$ & 2 & 0 & 0 & 1 & 1 & 1 & 5 \\
\hline REEC & 1 & 1 & 0 & 0 & 0 & 0 & 2 \\
\hline EENCI & 2 & 1 & 2 & 0 & 0 & 0 & 5 \\
\hline IENCI & 1 & 0 & 0 & 0 & 0 & 0 & 1 \\
\hline $\mathrm{S} \& \mathrm{E}$ & 4 & 2 & 1 & 1 & 1 & 2 & 11 \\
\hline Total & 13 & 4 & 4 & 5 & 4 & 11 & 41 \\
\hline
\end{tabular}

É importante observar que as estratégias de ensino de história da ciência descritas por Mccomas (2013) não constituem categorias estanques e independentes. Por exemplo, geralmente os experimentos históricos são conduzidos apoiados por uma fonte primária. Na resolução do estudo de caso histórico podem ser utilizados experimentos históricos, fontes primárias, atividades de dramatização ou até mesmo biografia e autobiografia dos cientistas. Assim, para essa revisão, identificamos as estratégias de ensino de história da ciência predominante nos artigos.

De acordo com os dados transcritos na tabela 3, observamos uma diferença entre o número total de artigos encontrados nos periódicos (36) e, a distribuição total desses trabalhos em relação as estratégias de ensino (41). Isto acontece porque em quatro artigos revisados encontramos trabalhos que utiliza predominantemente duas ou mais estratégias de ensino de história da ciência: Rodrigues et al., 2012, utilizam em seu trabalho fontes originais, experimentos históricos e biografia e autobiografia dos cientistas; Silveira et al., 2010, e Silva e Martins, 2010, fontes originais e atividades de dramatização em seus trabalhos e Paraskevopoulou e 
Koloiopoulous, 2011, estudo de caso histórico e biografia e autobiografia como estratégias de ensino de história da ciência.

As fontes primárias como estratégia de ensino de história da ciência aparecem predominantemente em treze trabalhos: (BLOWN; BRYCE, 2013; BRAGA et al., 2012; BRICCIA; CARVALHO, 2011; GAULD, 2010; GUERRA et al., 2013; OLIVEIRA et al., 2013; PENEREIRO, 2010; RODRIGUES et al., 2012; SILVA; MARTINS, 2010; SILVA et al., 2011; SILVEIRA et al., 2010; TEIXEIRA et al., 2010; ZANOTELLO, 2011).

O estudo de caso histórico como principal estratégia de ensino de história da ciência aparece em quatro trabalhos (HYGINO et al., 2012; HYGINO et al., 2013; DUCHEYNE, 2012; PARASKEVOPOULOU; KOLOIOPOULOUS, 2011).

Quatro trabalhos utilizam predominantemente atividades de dramatização como estratégia de ensino: MEDINA; BRAGA, 2010; PILIOURAS et al., 2011; SILVEIRA et al., 2010; SILVA; MARTINS, 2010.

Verificamos em nossa revisão que cinco trabalhos utilizam principalmente os experimentos históricos em suas aulas: BRENNI, 2012; FRANCISQUINI et al., 2014; RINALDI; GUERRA, 2011; JUNIOR et al., 2012; RODRIGUES et al., 2012.

A utilização da biografia e/ou autobiografia dos cientistas como principal estratégia de ensino de história da ciência estão presentes em quatro trabalhos da nossa revisão: CORDEIRO; PEDUZZI, 2010, 2011; PARASKEVOPOULOU; KOLOIOPOULOUS, 2011; RODRIGUES et al., 2012.

Verificamos que onze trabalhos têm como objetivo analisar a história da ciência presente nos livros didáticos: Coelho, 2010; Cordeiro; Peduzzi, 2013; Gomes, 2012; Gomes; Pietrocola, 2011; Klassen et al., 2012; Krapas, 2011; Neto; Junior, 2013; Pena; Teixeira, 2013; Nóbrega et al., 2013; Ramirez et al., 2010; e Urias; Assis, 2012.

\section{IV.2 Etapa interpretativa}

\section{IV.2.1 A seleção das unidades empíricas e teóricas}

As unidades empíricas (UE) correspondem a fragmentos de textos (frases ou parágrafos) retirados do corpus e transcritos literalmente. Nosso corpus são os 36 artigos selecionados de acordo com os critérios descritos no item III.1 desse trabalho.

As unidades teóricas (UT) são citações literais ou não de outros autores que não pertencem ao corpus e que estão relacionados com as unidades empíricas. Podem ser livros ou artigos.

As unidades empíricas e teóricas recebem um código e um título. Assim:

O código ART14.UE01 representa a $1^{\text {a }}$ unidade empírica selecionada do artigo 14 . O código deve receber um título, nesse caso: "pêndulo simples" (quadro 1)

O código REF06. UT01 representa a 1 ${ }^{a}$ unidade teórica selecionada da referência 06. O código deve receber um título, nesse caso: "dar sentido as equações” (quadro 1). 
O código ART24.UE04 representa a $4^{\mathrm{a}}$ unidade empírica selecionada do artigo 24. O código deve receber um título, nesse caso: "produção coletiva do conhecimento" (quadro 2).

O código REF14.UT01 representa a $1^{\text {a }}$ unidade teórica referência 05 . O código deve receber um título, nesse caso: "trabalho em equipe" (quadro 2)

O código ART24.UE05 representa a $5^{\text {a }}$ unidade empírica selecionada do artigo 24. O código deve receber um título, nesse caso: "registro do professor" (quadro 3).

O código REF15.UT01 representa a $1^{\text {a }}$ unidade teórica selecionada da referência 15. O código deve receber um título, nesse caso: "registro das observações" (quadro 3).

A seguir encontram-se exemplos de unidades empíricas e teóricas retiradas da nossa revisão:

Quadro 1 - Exemplos de unidades empírica e unidade teórica sobre conceitos científicos.

Unidade empírica (UE):

ART14.UE01 - Pêndulo Simples

"...uma aprendizagem mais rica e significativa de conceitos relacionados ao período de oscilação do pêndulo simples" (HYGINO et al., 2012)

Unidade teórica correspondente (UT):

REF06.UT01- dar sentido às equações

"Embora a História e a Filosofia da Ciência não sejam meros "instrumentos" para a compreensão do conteúdo específico, elas podem ajudar a dar um maior significado às equações e "fórmulas" que os estudantes associam à Física, em particular. É comum ouvirmos estudantes dizendo que "decoraram" alguma equação, por exemplo, mas que não compreendem o seu significado. A História e a Filosofia podem buscar a origem dessa equação e inseri-la na problemática precisa de uma época, dando sentido ao que - descontextualizadamente - parecia estar "solto" (FERREIRA e MARTINS, 2008).

Quadro 2 - Exemplos de unidade empírica e unidade teórica sobre a natureza da ciência.

Unidade empírica (UE):

ART24.UE04 - produção coletiva do conhecimento

[..] sozinhos, os cientistas não produzem nada (RINNALDI; GUERRA, 2011)

Unidade teórica correspondente (UT)

REF14.UT01- trabalho em equipe

"O trabalho em equipe pode apresentar duas formas: pode ser simplesmente aditivo, como, por exemplo, o levantar em comum um peso, ou pode ser um trabalho coletivo propriamente dito que consiste em criar, mediante o esforço conjunto, uma estrutura especial que não é igual à soma dos trabalhos individuais e é comparável a uma partida de futebol, a uma conversação ou o atuar de uma orquestra. Como poderia considerar-se a atuação de uma orquestra, passando por alto o significado e as regras de cooperação, como a mera soma do trabalho dos instrumentos individuais?" (FLECK, 1986, p. 145) 
Quadro 3 - Exemplos de unidade empírica e unidade teórica sobre instrumentos de coleta de dados.

Unidade empírica (UE)

ART24. UE05- registro do professor

Os dados obtidos através desse diário foram complementados com filmagens e gravações

de áudio (RINALDI e GUERRA, 2011).

Unidade teórica correspondente (UT)

REF15. UT01- registro das observações

"[...] as anotações escritas podem vir combinadas com gravações, filmes, fotografias, slides e outros equipamentos" (LUDKE e ANDRÉ,1986, p.32)

\section{IV.2.2 Comunicação através dos metatextos}

A seguir encontram-se os seis metatextos provenientes da análise do pesquisador utilizando a técnica ATD a partir das categorias definidas a priori por McComas (2013). Essas categorias contemplam distintas estratégias didáticas para o ensino de história da ciência em aulas de física tais como o uso das fontes primárias ou originais, dos estudos de caso histórico, das atividades de dramatização, dos experimentos históricos, das biografias e/ou autobiografias dos cientistas e, da análise de conteúdos de história da ciência presentes nos livros didáticos. Identificamos no nosso corpus dois objetivos de aprendizagem: o primeiro relacionado aos conceitos físicos e o segundo em aspectos relacionados ao entendimento da natureza da ciência. Identificamos também, no nosso corpus, os instrumentos de avaliação utilizados pelos autores para mensurar o conhecimento dos alunos.

\section{Metatexto - fonte primária}

As fontes primárias representam a abordagem da história da ciência na qual os alunos estudam conceitos vigentes da época a partir dos escritos dos cientistas e então participam de discussões sobre o que eles estudaram (MCCOMAS, 2013, p.432). Ainda segundo esse autor a interação com trabalhos originais pode ser classificada como: a) trabalhos originais completos (podem incluir comentários originais) e trabalhos originais resumidos (podem incluir comentários adicionais). As fontes primárias, como estratégia de ensino de história da ciência, aparecem em treze trabalhos: (BLOWN; BRYCE, 2013; BRAGA et al., 2012; BRICCIA; CARVALHO, 2011; GAULD, 2010; GUERRA et al., 2013; OLIVEIRA et al., 2013; PENEREIRO, 2010; RODRIGUES et al., 2012; SILVA; MARTINS, 2010; SILVA et al., 2011; SILVEIRA et al., 2010; TEIXEIRA et al., 2010; ZANOTELLO, 2011).

Identificamos nos artigos que a principal finalidade dessa intervenção pedagógica é fazer com que os estudantes possam compreender a evolução dos conceitos de física e aspectos da natureza da ciência através da utilização de episódios históricos. Para mensurar a evolução do aprendizado do discente os autores dos artigos usaram diversos instrumentos de coleta de dados. 
A evolução dos conceitos de física estava presentes em grande parte dos artigos e [...] serviram para mostrar que os conceitos devem ser analisados dentro de uma concepção de mundo (SILVEIRA et al., 2010) para que os alunos reconheçam a ruptura de um modelo anteriormente aceito e a consequente passagem para um novo modelo, destacando que os conhecimentos da ciência são vivos, abertos, sujeitos a mudanças e reformulações (BRICCIA; CARVALHO, 2011) revelando assim, a potencialidade do texto histórico em trabalhar a evolução de conceitos científicos com os alunos (SILVA; MARTINS, 2010). A leitura de fontes primárias contribui para uma postura um pouco mais crítica em relação à evolução dos conceitos científicos (ZANOTTELLO, 2011) como, por exemplo, a dedução matemática da lei da GU de Newton (TEIXEIRA et al., 2010) e a investigação do pensamento do aluno sobre a lei da gravidade em diferentes culturas (BLOWN; BRYCE, 2013), o que auxilia o professor a promover um elo entre o ensino fundamental e médio (GLAUD, 2010).

Klassen (2010) propõe uma orientação para construir narrativas históricas da ciência que podem auxiliar o professor na elaboração das hipóteses e explicações da evolução dos conceitos da física:

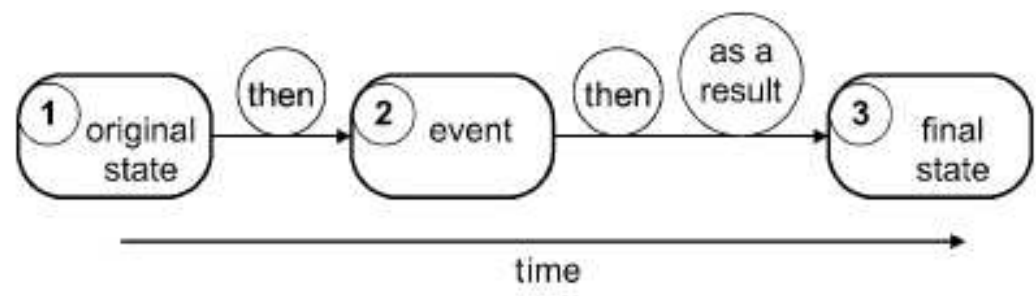

Fig. 2 - Sequência de narrativa histórica segundo Klassen (2010).

A Fig. 2 retrata a construção de narrativas em que os estados iniciais e finais apresentam uma relação inversa. $\mathrm{O}$ autor fornece um exemplo de narrativa histórica, construída de acordo com a Fig. 1:

"Ohm compreendeu a teoria matemática do calor, então, por analogia, ele aplicou a teoria para a eletricidade, e então, como resultado ohm compreendeu a teoria da resistência elétrica" (KLASSEN, 2010, p. 308).

Em relação aos aspectos da natureza da ciência, a fonte primária foi mais utilizada como possibilidade de trabalhar na sala de aula as controvérsias científicas que ocorreram na história da ciência. As controvérsias científicas são desvios de percurso "canônico" do desenvolvimento científico ou episódios que dizem respeito às relações interpessoais ou ainda disputas entre os defensores de dois modos diversos de teorização de determinados fenômenos (GAVROGLU, 2007, p. 189). Segundo esse autor "para se classificar de controvérsia, uma discordância científica, será preciso que esta tenha uma razoável duração temporal e que as partes envolvidas formulem publicamente os seus argumentos e contra-argumentos" (GAVROGLU, 2007, p. 190). 
Os artigos científicos presentes na nossa revisão abordam as controvérsias científicas através da utilização das fontes primárias no ensino. Os aspectos da natureza da ciência trabalhados nesses artigos têm como objetivo colocar o leitor frente a frente com seu modo de atuar, pensar e proceder no plano científico (PENEREIRO, 2010), como a controvérsia existente acerca da natureza da luz, principalmente nos séculos XVII e XVIII (SILVA; MARTINS, 2010) ou a do século XIX entre os físicos franceses Biot e Ampère sobre as interpretações distintas em relação ao experimento de Oersted (BRAGA et al., 2013). Estes exemplos combatem a ideia de que o conhecimento científico seja fruto de um conhecimento linear, puramente acumulativo (BRICCIA e CARVALHO, 2011) e reforçam a influência dos fatores histórico, social e cultural no desenvolvimento científico (GUERRA et al., 2013), não desprezando o conteúdo metafísico (OLIVEIRA et al., 2013), enriquecendo significativamente o conteúdo da Física, dando vida a essa matéria que é fria (RODRIGUES et al., 2012).

A abordagem dos aspectos sociais no ensino permite ao aluno compreender as visões adequadas da natureza da ciência evitando a visão socialmente neutra da ciência descrita por Gil Pérez et al (2001) como uma visão que negligencia as "complexas relações entre ciência, tecnologia, sociedade (CTS)". Deve-se também combater a visão acumulativa da ciência entendida por Gil Pérez et al. (2001) como "uma interpretação simplista da evolução dos conhecimentos científicos, para a qual o ensino pode contribuir ao apresentar os conhecimentos hoje aceitos sem mostrar como eles foram alcançados, não se referindo às frequentes confrontações entre teorias rivais, às controvérsias científicas, nem aos complexos processos de mudança".

Os instrumentos para coleta de dados apresentados nos artigos, com o objetivo de favorecer a aprendizagem de conceitos científicos e aspectos da natureza da ciência com a utilização de fontes primárias foram diversificados e ocorreu através de um teste diagnóstico que permitiu ao aluno ter um momento próprio para elaborar suas ideias sobre o tema que iria ser estudado (SILVA; MARTINS, 2010) ou responder a um questionário proposto sobre os textos (BRAGA et al., 2012; ZANOTTELLO, 2011).

As atividades realizadas pelos alunos foram dinâmicas e variadas como leitura, elaboração de cartazes e encenação, que envolveram tanto a parte conceitual quanto histórica sobre movimento relativo (SILVEIRA et al., 2010) ou a utilização da multimídia que permitiram aos alunos comparar os textos que fazem parte da multimídia com os dos livros didáticos (RODRIGUES et al, 2012). Tais alunos relataram que os textos apresentados nos livros didáticos não os ajudam, pelo contrário, dificultam o entendimento dos conceitos (RODRIGUES et al., 2012).

Outro instrumento para coleta de dados identificado nos artigos foi a utilização de vídeos. Utilizando uma aula expositiva dialogada e gravada o professor questiona os estudantes: [...] Pessoal, o que é que o Rumford fazia? Trabalhava onde? (BRICCIA; CARVALHO, 2011).

A diversidade dos instrumentos para a coleta de dados também está presente no trabalho de Blown e Bryce (2013), onde ele aplica as estratégias de Piaget [...] linguagem verbal, 
desenho e massa de modelar (BLOWN; BRYCE, 2013) para representar as concepções das crianças sobre a forma e movimento da Terra e, a queda dos corpos em países distintos.

Os outros artigos não tiveram coleta de dados (GLAUD, 2010; OLIVEIRA et al., et 2013; TEIXEIRA al., 2010) mas apresentaram orientações significativas para o ensino e aprendizagem da história da ciência.

Percebe-se que existe uma pluralidade de instrumentos utilizados para coleta de dados como questionários, desenhos, massa de modelar, registros oral e gravado, etc. Um trabalho que pode ser adotado como referência para coleta de dados é o de Boss et al. (2011). Este autor identifica algumas dificuldades dos licenciandos em física quanto à leitura e entendimento das traduções de fonte primária. As etapas descritas pelos autores supracitados são constituídas por duas fases: a primeira consiste na coleta de dados para verificar quais as dificuldades de leitura e entendimento que graduandos em física reportariam ao lerem uma tradução de fonte primária. A sequência sugerida para a coleta de dados dessa fase é: a) leitura do texto b) responder as perguntas (sem o texto em mãos): Qual o assunto abordado no texto? e $\mathrm{O}$ que foi compreendido do texto? A segunda fase consiste na aplicação de um excerto de fonte primária de duas formas distintas: a) sem figura e sem comentários b) com figuras e com comentários. Para cada forma distinta o aluno deverá anotar em um caderno suas dificuldades de leitura, caso exista; as dificuldades de entendimento caso exista; apresentar sugestões para facilitar a leitura e o seu entendimento e explicar o que compreendeu do texto.

\section{Metatexto - estudo de caso histórico}

De acordo com Stinner (2003), o estudo de caso histórico se caracteriza por princípios gerais que possibilitem o resgate do contexto em que se deu algum problema marcante na ciência. Segundo este autor um bom estudo de caso deve conter o contexto histórico, o experimento e a ideia principal e a implicações para a alfabetização científica e o ensino de ciências. O uso de estudo de caso no contexto educacional proveniente de algum episódio histórico favorece, de acordo com El Hani (2006), a aprendizagem dos conceitos físicos e permite a reflexão dos aspectos da natureza da ciência, pois possibilita um estudo detalhado dos fatos históricos, sociais e culturais envolvidos no trabalho científico. De acordo com McComas (2013) a abordagem de estudo de caso ou método de caso para o ensino tem sido muito utilizada em diversas disciplinas e, a ciência não é exceção.

O estudo de caso histórico como principal estratégia de ensino de história da ciência aparece em quatro trabalhos (HYGINO et al., 2012; HYGINO et al., 2013; DUCHEYNE, 2012; PARASKEVOPOULOU; KOLOIOPOULOUS, 2011).

Identificamos nos artigos que a principal finalidade dessa intervenção pedagógica é fazer com que os estudantes possam compreender a evolução dos conceitos de física e aspectos da natureza da ciência através da utilização de episódios históricos. Para mensurar a evolução do aprendizado do discente os autores dos artigos usaram principalmente questionários e recolhimentos de textos. 
Em relação aos conceitos científicos, identificamos nos artigos que a estratégia do estudo de caso permite: uma aprendizagem mais rica e significativa de conceitos relacionados ao período de oscilação do pêndulo simples (HYGINO et al., 2012) e favorece o conhecimento mais amplo dos conceitos envolvidos no desenvolvimento da óptica geométrica e da astronomia, levando, assim, mais significado aos temas abordados em sala de aula (HYGINO et al., 2013). A estratégia do estudo de caso possibilita compreender também o argumento de Millikan sobre a existência de carga elétrica elementar (PARASKEVOPOULOU; KOLIOPOULOS, 2011) e de Ehrenhaft, sobre a existência de carga elétrica fracionada (sub-elétrons) (PARASKEVOPOULOU; KOLIOPOULOS, 2011) e as interações gravitacionais entre corpos (DUCHEYNE, 2012). Essas interações foram determinadas através do experimento de Cavendish.

O estudo dos conceitos científicos via história e filosofia da ciência permite que o aluno entenda os pormenores da evolução conceitual do conteúdo evitando assim o aprendizado adquirido apenas pela memorização de fórmulas soltas. Assim,

\footnotetext{
Embora a História e a Filosofia da Ciência não sejam meros "instrumentos" para a compreensão do conteúdo específico, elas podem ajudar a dar um maior significado às equações e "fórmulas" que os estudantes associam à Física, em particular. É comum ouvirmos estudantes dizendo que "decoraram" alguma equação, por exemplo, mas que não compreendem o seu significado. A História e a Filosofia podem buscar a origem dessa equação e inseri-la na problemática precisa de uma época, dando sentido ao que - descontextualizadamente - parecia estar "solto" (FERREIRA; MARTINS, 2008).
}

Em relação aos aspectos da natureza da ciência presente nessa intervenção pedagógica, a utilização do estudo de caso histórico nos artigos revisados tem como objetivo problematizar as visões sobre a natureza da ciência dos alunos e contribuir para que visões mais adequadas da atividade científica fossem consideradas (HYGINO et al., 2012), reconhecendo a ciência como uma atividade coletiva (HYGINO et al., 2013) e que a ciência envolve testes contínuos e cada vez mais rigorosos da teoria, que se forem bem sucedidos, resultam em evidência cada vez mais forte para a manutenção da teoria (DUCHEYNE, 2012). O estudo da natureza da ciência evita o entendimento equivocado de que o processo de construção do conhecimento científico ocorre por descobertas alcançadas a partir de observações neutras (HYGINO et al., 2013).

Outro aspecto da natureza da ciência encontrado nessa revisão foi a utilização da controvérsia científica associada ao debate entre Millikan e Ehrenhaft sobre a existência ou não da carga elétrica elementar, o que permitiu os professores questionar seus alunos do ensino médio sobre a possibilidade desses dois cientistas alcançarem conclusões distintas a partir da observação dos mesmos dados. A resposta envolve considerações sobre o "aspecto subjetivo da NDC (PARASKEVOPOULOU; KOLOIOPOULOUS, 2011).

Os aspectos da natureza da ciência trabalhados com os estudos de caso têm como foco evitar as visões deformadas do trabalho científico identificadas por Gil Peréz et al. (2001) como 
a visão empírico-indutivista, concepção que destaca o papel "neutro" da observação e da experimentação; a visão rígida no qual se mostra "método científico" como um conjunto de etapas a seguir mecanicamente, a visão individualista e elitista da ciência, que descarta o caráter coletivo da construção do conhecimento científico.

A unidade empírica citada por Ducheyne (2012) se refere aos testes realizados com a experiência de Cavendish para verificação das interações gravitacionais entre dois corpos.

Os instrumentos para coleta de dados apresentados nos artigos com a aplicação do estudo de caso foram questionários e textos recolhidos com o auxílio de um espaço virtual de aprendizagem (EVA). A escolha desse espaço virtual tinha por objetivo contornar algumas limitações de tempo (HYGINO et al., 2013). Foi solicitado aos alunos do PROEJA que realizassem uma sequência de três etapas: A primeira consistia de uma leitura do estudo de caso (HYGINO et al, 2012), para colher os seus conhecimentos prévios e, após outras leituras (segundo passo) os alunos deveriam enviar pelo EVA [...] suas respostas finais, incorporando elementos das leituras e discussões realizadas (HYGINO et al., 2012), o que caracteriza o terceiro passo. Assim, a coleta de dados nesta pesquisa ocorreu por meio do próprio EVA, mais especificamente pelo armazenamento das respostas textuais produzidas pelos estudantes aos três passos do Estudo de Caso (HYGINO et al., 2013) ou através de questionário distribuído antes e depois da aula (PARASKEVOPOULOU; KOLOIOPOULOUS, 2011). Não houve instrumento de avaliação no artigo escrito por Ducheyne (2012).

Os três passos supracitados para a resolução do estudo de caso ressoam nas etapas do estudo de caso descritos por Reis e Linhares (2011):

$1^{a}$ fase: leitura do texto e imediata postagem no ambiente virtual de aprendizagem de uma resposta que indicará a concepção do aprendiz em relação a uma questão.

$2^{a}$ fase: tempo para ler, resenhar e discutir materiais disponibilizados no ambiente.

$3^{a}$ fase: elaboração de solução que deve ser defendida pelo aprendiz perante o professor e os colegas no ambiente virtual de aprendizagem elou presencialmente (REIS; LINHARES, 2011)

Tão importante quanto às etapas descritas para a resolução do estudo de caso de Reis e Linhares (2011) é a aplicação do questionário antes e depois do estudo de caso, com o objetivo de mensurar explicitamente a evolução do conhecimento discente. Essa intervenção permite um envolvimento dinâmico do estudante nas atividades de ensino, transformando-o em "participante ativo de seu processo de aprendizagem" (ZÔMPERO; LABURU, 2011).

\section{Metatexto - Dramatização}

Dramatização são estratégias de ensino nas quais os alunos interpretam personagens da história da ciência com o objetivo de agir, debater ou responder como se fossem essas pessoas (MCCOMAS, 2013, p.438). Uma encenação na sala de aula dos debates entre Simplício 
(defensor das ideias de Aristóteles) e Salviatti (defensor das ideias de Galileu) ou produção de filmes embasados em debates históricos são exemplos de atividades que envolvam dramatização.

Quatro trabalhos utilizam predominantemente atividades de dramatização como estratégia de ensino (MEDINA; BRAGA, 2010; PILOURAS, 2011; SILVEIRA et al., 2010; SILVA; MARTINS, 2010).

Identificamos nos artigos que a principal finalidade dessa intervenção pedagógica é estudar aspectos da natureza da ciência e conceito científico através das controvérsias científicas. Para mensurar a evolução do aprendizado do discente os autores dos artigos usaram questionários, desenhos e entrevistas de grupo focal.

Controvérsia científica pode ser entendida "como uma disputa conduzida publicamente e mantida persistentemente, sobre um assunto de opinião considerado significativo por um número de cientistas praticantes" (NARASIMHAN, 2001, p. 299).

Assim, para que as controvérsias científicas se transformem em uma discordância científica os cientistas devem publicar os seus trabalhos em artigos científicos, livros ou outras fontes confiáveis; como aconteceu em 1510, num curto texto manuscrito chamado Commentariolus e, em 1543, na obra As Revoluções das Orbes Celestes, no qual Nicolau Copérnico apresentou sua teoria heliostática (FERREIRA; MARTINS, 2008), criticando a teoria aristotélica, dando início a uma duradoura controvérsia científica.

As controvérsias científicas trabalhadas com a utilização da dramatização aconteceram através da produção de filmes de animação sobre a debate geocêntrico-heliocêntrico inspirado na história da ciência (PILIOURAS et al., 2011) construídos por alunos do ensino fundamental, ou por encenação de uma peça teatral que ocorre como parte de um trabalho sobre a revolução científica, técnica, artística, econômica e social ocorrida durante os séculos XVI e XVII (MEDINA; BRAGA, 2013) produzidos por alunos do primeiro ano do ensino médio. A atividade de dramatização também foi encenada por alunos do segundo ano do ensino médio através de dinâmica de grupo chamada de "júri simulado" (SILVA; MARTINS, 2010) com o objetivo de debater "as controvérsias geradas em torno da natureza da luz (onda ou partícula?) (SILVA; MARTINS, 2010).

Foi ainda desenvolvida com alunos do primeiro ano do ensino médio uma oficina teatral baseada num recorte de texto extraído do livro de Galileu, "Diálogo sobre os dois maiores sistemas de mundo" (SILVEIRA et al., 2010) para mostrar as discussões sobre as ideias de Aristóteles e Galileu sobre o movimento relativo (SILVEIRA et al., 2010). Os aspectos da natureza da ciência trabalhados com essas controvérsias permitem entender que as ideias de Aristóteles têm implícito o método apriorístico, ou seja, o movimento ocorre porque existe uma causa maior ${ }^{6}$, intrínseca ao próprio movimento [...]. Por outro lado, Galileu observa esse movimento de outra maneira, imerso no empirismo do século XVII, descrevendo experimentos

\footnotetext{
6 O princípio intrínseco de Aristóteles como um princípio metafísico, era comum e coerente para sua época. Mais detalhes, ver Peduzzi (1996).
} 
(SILVEIRA et al., 2010). Essas controvérsias permitem compreender a importância do contexto para a validade das leis, bem como o processo de construção do conhecimento, com a ruptura das ideias Aristotélicas (SILVEIRA et al., 2010) mostrando que o conhecimento é dinâmico (SILVA; MARTINS, 2010) e que acontecem novas interpretações científicas que substitui as antigas à luz de novas evidências (PILIOURAS et al., 2011).

Os aspectos da natureza da ciência presentes nas unidades empíricas supracitadas permitem discutir se as observações "são dependentes da teoria" (FERREIRA, 2013) e se "as teorias científicas não são induções, mas hipóteses que vão imaginativa e necessariamente além das observações" (FERREIRA, 2013). Esse entendimento evita a concepção empírico-indutivista e ateórica no qual se caracteriza por uma visão deformada do trabalho científico que é entendida como "uma concepção que destaca o papel "neutro" da observação e da experimentação (não influenciadas por ideias apriorísticas), esquecendo o papel essencial das hipóteses como orientadoras da investigação, assim como dos corpos coerentes de conhecimentos (teorias) disponíveis, que orientam todo o processo" (GIL PÉREZ et al., 2001)

Ainda em relação à natureza da ciência os artigos revelam que as ideias científicas são afetadas pelo meio social e histórico no qual são construídas (SILVA; MARTINS, 2010) e pela cultura (PILIOURAS et al., 2011). Estas relações entre a ciência e seu contexto humano e social ficam totalmente esquecidos ou mesmo ausentes das aulas tradicionais das disciplinas científicas (MEDINA; BRAGA, 2010) que transmitem a ideia de um método científico único (SILVEIRA et al., 2010).

A dependência da ciência dos fatores sociais é um dos aspectos da visão consensual ${ }^{7}$ descrito por Lederman et al. (2002). Para Matthews (2012) o fator social é apenas um fator externo do desenvolvimento científico. Segundo ele, a ciência depende também da tecnologia, da matemática, da comunicação, do dinheiro, da educação, da filosofia e da cultura de uma forma mais abrangente.

Embora a ênfase maior tenha sido dada aos aspectos da natureza da ciência, os conceitos de física também estiveram presentes nas atividades de dramatização, dos artigos da nossa revisão. Foram abordados conceitos como velocidade da luz/ reflexão/ refração [...] difração, interferência (SILVA; MARTINS, 2010) e de referencial em movimento (SILVEIRA et al., 2010) ou conceitos da mecânica clássica, implícitos na obra A vida de Galileu Galilei, de Bertolt Brecht (MEDINA; BRAGA, 2010), ou da mecânica celeste representada pelo "movimento dos planetas ao redor do redor do sol [..] na curta-metragem produzida pelos alunos (PILIOURAS et al., 2011).

A compreensão dos conceitos de física é relevante para o aprendizado do aluno porque evita o entendimento da ciência advinda apenas de opiniões pessoais. Segundo essa visão

\footnotetext{
7 A “visão consensual” é baseada, principalmente, em oito documentos oficias de educação científica, cuja análise levou à construção dos princípios sobre a natureza da ciência. Esse conjunto de princípios contém proposições curtas, diretas e de caráter geral sobre a ciência (MARTINS; RYDER, 2014)
} 
“aquilo que é considerado melhor ou pior em relação às teorias científicas variará de indivíduo para indivíduo e de comunidade para comunidade" (CHALMERS, 2009, p. 137).

Os instrumentos para coleta de dados apresentados nos artigos que utilizam da estratégia de dramatização aconteceram através dos filmes de animação produzidos pelos alunos, questionários, entrevistas e desenhos (PILIOURAS et al., 2011), por anotações do professor em relação a assiduidade e comportamento dos alunos durante as atividades, postura frente aos conflitos surgidos no desenvolvimento do projeto, fontes de consulta e formas de resolução dos problemas encontrados (MEDINA; BRAGA, 2010) e através de entrevista "focus group" (MEDINA; BRAGA, 2010). O Grupo Focal ou "focus group" consiste na interação entre os participantes e o pesquisador e a coleta de dados, a partir da discussão com foco, em tópicos específicos e diretivos (IERVOLINO; PELICIONE, 2001). Nos trabalhos de Silva e Martins (2010) e Silveira et al. (2010) não houve avaliação explícita das atividades de dramatização, apenas alguns relatos dos docentes sobre importância dessa estratégia de ensino.

Essa revisão mostrou que as atividades de dramatização podem contribuir para a explicação das controvérsias científicas. Os filmes de curta metragem produzidos pelos alunos do ensino fundamental serviram como recurso introdutório para a compreensão de uma visão de mundo menos fragmentada do ensino, porque os alunos aprenderam a relacionar a física com aspectos religiosos. $\mathrm{O}$ uso da peça teatral favoreceu o entendimento interdisciplinar da revolução cultural do século XVII na perspectiva das quatro revoluções específicas: científica, artística, político-religiosa e filosófica. Além disso, a peça teatral atendeu satisfatoriamente às competências: I. Dominar linguagens (DL); II. Compreender fenômenos (CF) e IV. Construir argumentação (CA): sugeridas pelo INEP/ENEM. O júri simulado foi uma atividade motivadora e promoveu uma maior cooperação entre os discentes. Já o estudo e a encenação presentes no livro do diálogo entre os personagens de Galileu permitiram compreender as discordâncias entre teorias.

\section{Metatexto - experimentos históricos}

Os experimentos históricos consistem na reprodução de experimentos e outras abordagens práticas para o engajamento com alguns aspectos históricos da ciência (MCCOMAS, 2013, p.440).

Verificamos em nossa revisão que cinco trabalhos utilizam principalmente os experimentos históricos em suas aulas (BRENNI, 2012; FRANCISQUINI et al., 2014; RINALDI; GUERRA, 2011; JUNIOR et al., 2012; RODRIGUES et al., 2012).

$\mathrm{O}$ foco principal dos artigos dessa revisão é abordar os conceitos físicos presentes nas réplicas dos experimentos históricos. No entanto, encontramos implicitamente, em alguns deles, trechos que evidenciam aspectos da natureza da ciência. Para mensurar a evolução do aprendizado do discente os autores dos artigos usaram questionários, entrevistas e filmagem.

A explicação dos conceitos físicos foi mediada por réplicas de experimentos históricos para os professores mostrar aos alunos do ensino médio o conceito de queda livre através da 
solução do paradoxo cinemático aparente (FRANCISQUINI, 2014) ou pela Simulação Didática Interativa (SDI), utilizando o software Modellus para apresentar a experiência do plano inclinado (JUNIOR et al., 2012). Tanto o paradoxo como o plano inclinado foram descritos na obra "Discursos e Demonstrações Matemáticas em Torno de Duas Novas Ciências (1638)" de Galileu Galilei. O conceito de movimento foi trabalhado a partir da confecção de modelos planetários: geocêntrico e heliocêntrico (RODRIGUES, et al., 2012). Os conceitos de corrente elétrica e o processo de armazenamento de carga elétrica (funcionamento de um capacitor), foram trabalhados respectivamente através da construção de uma réplica da pilha de volta [...] e da garrafa de Leyden rudimentar (RINNALDI; GUERRA, 2011) com o objetivo de subsidiar o aluno do ensino médio para a construção de um transmissor de ondas eletromagnéticas rudimentar (RINNALDI; GUERRA, 2011). Os conceitos físicos também estão presentes no artigo de Brenni (2012), no qual descreve a evolução dos experimentos didáticos de física e seus usos pelos professores desde 1800 até 1930 . Ele afirma que desde 1820 cerca de novos instrumentos didáticos foram introduzidas em conexão com o rápido desenvolvimento da física como a óptica, ondas, eletromagnetismo e acústica (BRENNI, 2012).

Para Martins (2007) a história e da filosofia da ciência ajuda o aluno a entender melhor os conteúdos e a origem dos conceitos. Esses conceitos não emergem naturalmente da experiência. Assim, deve-se evitar perpetuar na sala de aula a visão empírico- indutivista da ciência, entendida como "uma concepção que destaca o papel "neutro" da observação e da experimentação (não influenciadas por ideias apriorísticas), esquecendo o papel essencial das hipóteses como orientadoras da investigação." (FORATO et al., 2011).

Em relação aos aspectos da natureza da ciência a reprodução dos experimentos históricos propicia um trabalho articulado entre as dimensões histórica e empírica da ciência (JUNIOR et al, 2012) e o contexto sociocultural (RINNALDI; GUERRA, 2011) para o aluno entender que sozinhos, os cientistas não produzem nada (RINNALDI; GUERRA, 2011). A reprodução dos experimentos históricos enriquece significativamente o conteúdo da Física, dando vida a essa matéria que é fria (RODRIGUES et al., 2012) porque atrai imediatamente a atenção dos estudantes (FRANCISQUINI, 2014) e evita a explicação dos experimentos históricos através de uma abordagem indutiva (BRENNI, 2012).

A revelação dos aspectos sociais permite ao estudante entender a ciência como uma contribuição coletiva evitando que ele entenda a ciência como uma concepção individualista e elitista no qual "os conhecimentos científicos aparecem como obras de gênios isolados, ignorando-se o papel do trabalho coletivo e cooperativo, dos intercâmbios entre equipes" (GIL PÉREZ et al 2001).

Ludwig Fleck (1896-1961) explica que a ciência é um empreendimento coletivo, porém o trabalho em equipe não acontece simplesmente pela sobreposição das contribuições individuais:

O trabalho em equipe pode apresentar duas formas: pode ser simplesmente aditivo, como, por exemplo, o levantar em comum um peso, ou pode ser um trabalho coletivo 
propriamente dito que consiste em criar, mediante o esforço conjunto, uma estrutura especial que não é igual à soma dos trabalhos individuais e é comparável a uma partida de futebol, a uma conversação ou o atuar de uma orquestra. Como poderia considerar-se a atuação de uma orquestra, passando por alto o significado e as regras de cooperação, como a mera soma do trabalho dos instrumentos individuais? (FLECK, 1986, p.145)

Fleck, então, caracteriza os tipos de trabalho em equipe. Mas como acontece o processo de coletivização da ciência?

Reis (2014) comenta que a "coletivização não é somente ciência feita de forma coletiva, mas uma impossibilidade de se fazer ciência de forma individual” (REIS, 2014, p. 224). A autora mostra que principalmente a partir da segunda metade do século XX a ciência ganhou um ethos mais gerencial do que acadêmico devido à dependência da ciência com as atividades industriais.

Sugerimos trabalhar os experimentos históricos após a leitura de alguns textos históricos com o objetivo de evitar a explicação anacrônica das práticas, isto é explicar os conceitos científicos de acordo com o paradigma vigente (FORATO et al., 2009). Para evitar transmitir essas visões equivocadas da construção do trabalho científico, Metz et al. (2007) propõe uma sequência didática para a utilização dos experimentos históricos no ensino. Essa sequência consiste em quatro partes: a) o levantamento do problema e o estabelecimento do contexto de produção do experimento com a inclusão de informações sobre o cientista e seu entorno cultural. b) o desenho do experimento. Nesta fase, os estudantes interagem entre si e buscam solução para o problema levantado no item anterior. c) análise e interpretação dos resultados. Nesta etapa os estudantes comparam e contrastam suas ideias com o trabalho original e, d) os alunos explicam, com formalismo científico sua proposta de solução ao problema e estabelecem conexões com o cotidiano deles. Percebe-se que a intervenção pedagógica com essa sequência didática prioriza os conhecimentos prévios dos alunos, transcendendo dessa forma uma aula de laboratório com roteiro de trabalho pré-estabelecido. O uso incorreto desse roteiro reforça a visão empírico-indutivista da ciência, isto é, um olhar equivocado de que a teoria científica emerge dos dados obtidos na experiência (GIL PÉREZ et al., 2001; FERREIRA; MARTINS, 2008; SILVEIRA; OSTERMAN, 2002).

Os instrumentos para coleta de dados apresentados nos artigos que utilizam a estratégia dos experimentos históricos aconteceram através de um diário construído em torno da impressão do professor quanto ao desenvolvimento da proposta. Os dados obtidos através desse diário foram complementados com filmagens e gravações de áudio (RINALDI; GUERRA, 2011) e entrevistas semiestruturadas (RINALDI; GUERRA, 2011). Segundo Ludke e André (1986), as anotações escritas podem vir combinadas com gravações, filmes, fotografias, slides e outros equipamentos (LUDKE; ANDRÉ, 1986, p. 32). Ainda segundo esse autor "uma regra geral quando devem ser feitas as anotações é que, quanto mais próximo do momento da observação, maior sua acuidade" (LUDKE; ANDRÉ, 1986, p. 32). Ainda de acordo com Ludke e 
André (1986), "na entrevista, a relação que se cria é de interação, havendo uma atmosfera de influência recíproca entre pergunta e quem responde" (1986, p. 33). Entendemos que essa a entrevista cria um ambiente amigável entre professor e aluno. A tarefa de casa também serviu para mensurar o aprendizado do aluno: o professor sugeriu aos seus alunos do ensino médio que pesquisasse sobre o fenômeno das marés (RODRIGUES et al., 2012). Os outros artigos da revisão (BRENNI, 2012; JUNIOR et al., 2012; FRANCISQUINI, 2014) não fizeram observações empíricas com alunos.

\section{Metatexto - biografia e/ou autobiografia dos cientistas}

Segundo McComas (2013) a biografia e autobiografia é o relato da vida e/ou da pesquisa dos cientistas escritas por eles mesmos (autobiografia) ou por outra pessoa (biografia). A utilização da biografia e/ou autobiografia dos cientistas, como estratégia de ensino no ensino de física estão presentes em quatro trabalhos da nossa revisão (CORDEIRO; PEDUZZI, 2010, 2011; PARASKEVOPOULOU; KOLOIOPOULOUS, 2011; RODRIGUES et al., 2012)

Identificamos nos artigos a presença de elementos motivacionais, aspectos da natureza da ciência e de conceitos científicos. Para mensurar a evolução do aprendizado do discente os autores dos artigos usaram diversos instrumentos de coleta de dados.

Em relação aos aspectos motivacionais as Conferências Nobel ministradas pelo casal Curie é capaz de mostrar, por exemplo, os sentimentos e a reação do autor frente a uma nova descoberta, dificilmente encontrados em outros textos sobre o tema ganhador do prêmio [...] ou o obstáculo que o casal contornou enquanto pode: as doenças e os ferimentos causados pelo excesso de exposição à radioatividade [...] (CORDEIRO; PEDUZZI, 2010). A inserção da biografia e autobiografia na sala de aula permite encorajar os professores a ensinar aspectos NDC de uma forma mais sistemática (PARASKEVOPOULOU; KOLOIOPOULOUS, 2011) e deixa as aulas interessantes e motivadoras (RODRIGUES et al., 2012). O professor pode, por exemplo, trazer para a sala de aula aspectos da personalidade de Newton: ser humano teimoso, briguento, crente em Deus e cheio de defeitos (RODRIGUES et al., 2012)

Os aspectos motivacionais que história da ciência proporciona ao ensino se encontra em nível denominado por Seker e Guney (2011) de "nível de interesse". Neste nível se encontra as informações sobre a vida dos cientistas e propõe dois objetivos educacionais: humanizar as ciências e capturar o interesse do aluno para a lição de ciências.

A estratégia de ensino que envolve a biografia e autobiografia desta revisão, pode ser usada para explicar conceitos físicos porque ajudam na recapitulação histórica das descobertas da partícula alfa e dos isótopos (CORDEIRO; PEDUZZI, 2011) e nos estudos que levou a descoberta do polônio e depois ao rádio (CORDEIRO; PEDUZZI, 2010) ou as ideias de Isaac Newton sobre o movimento dos corpos, culminando na Lei da Gravitação Universal (RODRIGUES et al., 2012)

Mostrar a evolução dos conceitos de física na sala de aula permite que o aluno entenda que a construção do conhecimento científico é um processo dinâmico e mutável. Segundo 
Matthews (1995), a concepção da mutabilidade e instabilidade da ciência é considerada uma visão adequada da natureza da ciência e elucida a ideia de que o pensamento científico atual está sujeito à transformações.

Em relação aos aspectos da natureza da ciência presentes nessa intervenção pedagógica, a utilização da biografia e autobiografia dessa revisão oferece ao aluno do ensino superior a possibilidade para o entendimento de discussões relativas a aspectos do trabalho científico compartilhados por correntes epistemológicas pos-positivistas (CORDEIRO; PEDUZZI, 2011) como, a relação entre a ciência e sociedade revelada através da influência da descoberta da radioatividade na Geologia, na Meteorologia e na Medicina, apontando inclusive para o perigo que constitui os conhecimentos sobre o rádio e a radioatividade em mãos erradas (CORDEIRO; PEDUZZI, 2010). Outros aspectos da natureza da ciência que podem ser trabalhados na sala de aula são a criatividade e imaginação e distinção entre observação e inferência (PARASKEVOPOULOU; KOLOIOPOULOUS, 2011). Assim, os alunos compreenderiam que $a$ existência de uma carga elétrica elementar é uma intervenção humana não sendo, portanto, um fato objetivo inquestionável (PARASKEVOPOULOU; KOLOIOPOULOUS, 2011) e entenderiam a importância de uma hipótese apriorística presentes nas técnicas de concentração do rádio e do polônio (CORDEIRO; PEDUZZI, 2010). O estudo da natureza da ciência através da biografia e da autobiografia dos cientistas tem o objetivo também de contribuir para desmistificar a própria ideia do gênio solitário (CORDEIRO; PEDUZZI, 2011) e revelar o caráter mutável das ideias científicas (RODRIGUES et al., 2012).

Observamos a partir das unidades empíricas supracitadas, que a utilização da biografia e a autobiografia evitam que o aluno adquira as visões deformações do trabalho científico identificadas por Gil Pérez et al (2001) como: a) visão empírico-indutivista, concepção que destaca o papel "neutro" da observação e da experimentação ; da visão rígida no qual se mostra "método científico" como um conjunto de etapas a seguir mecanicamente, b) da visão individualista e elitista da ciência, que descarta o caráter coletivo da construção do conhecimento científico; c) da visão exclusivamente analítica, que desconsidera o caráter mutável da ciência esquecendose dos "esforços posteriores de unificação e de construção de corpos coerentes de conhecimentos cada vez mais amplos" d) da visão socialmente neutra da ciência que não considera as relações da ciência com a sociedade.

Os instrumentos para coleta de dados com o objetivo de mensurar a aprendizagem dos alunos dos conceitos científicos e aspectos da natureza da ciência ocorreu através de questionários distribuídos antes e depois da aula (PARASKEVOPOULOU; KOLOIOPOULOUS, 2011) e texto narrativo sobre a parte da vida de Newton que mais havia lhes chamado atenção (RODRIGUES et al., 2012) associado com a utilização de multimídia.

Os outros artigos não tiveram coleta de dados (CORDEIRO; PEDUZZI, 2010, 2011). No entanto apresentaram orientações significativas para o ensino e aprendizagem da história da ciência. 
Podemos inferir a partir do trabalho de Rodrigues et al. (2012) que o contato inicial do aluno com a descrição dos trabalhos de Newton em sua biografia pode influenciar no aprendizado do conteúdo de gravitação universal desde que a utilização dessa intervenção pedagógica esteja associada com filmes, imagens, animações, etc. Os resultados do trabalho de Paraskevopoulou e Koloiopoulous (2011) mostraram que houve uma melhora significativa nas concepções dos discentes em relação ao entendimento da diferença entre observação e inferência. Já os trabalhos de Cordeiro e Peduzzi (2010; 2011) revelam que os estudos das Conferências Nobel podem ser um bom instrumento para transmitir ao aluno visões adequadas do trabalho científico.

\section{Metatexto - livros didáticos}

Essa estratégia procura analisar os conteúdos de história da ciência veiculados nos livros didáticos, com o objetivo de auxiliar o professor a identificar os conceitos de história da ciência e, possíveis visões deformadas da natureza da ciência presentes nesses livros didáticos. De acordo com (MCCOMAS, 2013, p. 439), quando os cientistas são mencionados nos livros didáticos “... suas contribuições estão limitadas a poucas frases, talvez uma figura, e às datas de nascimento e morte”. Os conteúdos dessas frases, muitas vezes, estão associados somente a uma sequência cronológica de invenções atribuída ao cientista, reforçando assim uma visão linear da história da ciência, que omitem as crises e controvérsias no ensino (GIL PÉREZ et al., 2001; LEITE, 2002).

Verificamos que onze trabalhos têm como objetivo analisar a história da ciência presente nos livros didáticos (COELHO, 2010; CORDEIRO; PEDUZZI, 2013; GOMES, 2012; GOMES; PIETROCOLA, 2011; KLASSEN et al., 2012; KRAPAS, 2011; NETO; JUNIOR, 2013; PENA; TEIXEIRA, 2013; NÓBREGA et al., 2013; RAMIREZ et al., 2010; URIAS; ASSIS, 2012).

A principal finalidade dos artigos é proporcionar aos professores, elementos que possam facilitar a leitura crítica dos conceitos físicos presentes nos livros didáticos, através da reconstrução histórica desses conceitos e do trabalho dos cientistas. Para atingir esse objetivo os autores promovem uma análise de conteúdo desses livros com o objetivo de auxiliar o professor no entendimento de visões adequadas da evolução do conceito científico e da natureza da ciência. Além disso, os autores estabelecem critérios para a avaliação dos conteúdos de história da ciência presentes nos livros didáticos.

Em relação aos conceitos físicos a revisão mostrou: uma visão geral sobre a definição de força nos livros contemporâneos (COELHO, 2010); a dilatação do tempo e da contração das distâncias (URIAS; ASSIS, 2012) explicado em duas obras de divulgação científica; o papel dos livros-textos na consolidação da ótica quântica (NETO; JUNIOR, 2013); o declínio (GOMES, 2012) do conceito de calórico e, a descrição do modelo atômico de Bohr (RAMIREZ et al., 2010). Além desses conceitos os artigos evidenciaram as modificações sofridas pelo ex- 
perimento de "Stern-Gerlach", até a forma em que ele é apresentado nos livros didáticos (GOMES; PIETROCOLA, 2011) e como as versões originais dos enunciados da segunda lei da termodinâmica aparecem em livros atuais (NÓBREGA et al., 2013). A revisão mostrou ainda como ocorre transposição didática da radioatividade em um livro usado em disciplinas de estrutura da matéria e afins, na formação de professores e futuros cientistas. (CORDEIRO; PEDUZZI, 2013) e do saber relativo à luz como OEM ${ }^{8}$ (KRAPAS, 2011).

Os resultados encontrados pelos autores mostraram que a força é a causa da aceleração (COELHO, 2010) e as grandezas tempo e espaço na relatividade especial é explicada por meio de figuras (URIAS; ASSIS, 2012), em um dos livros de divulgação científica. Os resultados da revisão mostraram ainda que livros textos de ótica quântica foram produzidos a partir de notas de aula (NETO; JUNIOR, 2013) dos cursos de verão ministrados pelo físico Herch Moysés Nussenzveig na década de 1960.

Gomes e Pietrocola (2011) citam o experimento de Stern-Gerlach (SG) descrito em outro livro de física, do autor Nussenzveig, usado no curso superior de física. Ele diz que o experimento fora realizado com o auxílio de feixe de elétrons, embora até onde sabemos o experimento de SG com um feixe de elétrons nunca foi realizado, devido à grandes dificuldades experimentais (GOMES; PIETROCOLA ,2011).

Ramirez et al (2010) mostram uma clara diferença entre a proposta de Bohr (1913) (RAMIREZ et al., 2010) e, a transposição atual desse modelo nos livros didáticos.

Nóbrega et al (2013) revelam que o conceito de segunda lei da termodinâmica como conhecemos hoje se deve ao físico Enrico Fermi (prêmio Nobel em 1938). Esse conceito diz que é impossível realizar uma transformação cujo único resultado final seja transformar em trabalho o calor extraído de uma fonte que está na mesma temperatura (NÓBREGA et al., 2013).

Gomes (2012) revela que um dos fatores que contribuíram para o declínio do calórico foi a aceitação generalizada da teoria ondulatória da luz, a qual - combinada com a visão de que calor e luz são qualitativamente o mesmo fenômeno - sugeria que o calor, como a luz, é uma forma de movimento ondulatório em vez de uma substância (GOMES, 2012).

Cordeiro e Peduzzi (2013) mostram que a transposição didática de alguns conteúdos da mecânica quântica presentes nos livros didáticos, supostamente, pode facilitar o aprendizagem conceitual dos alunos apesar de não terem relação histórica, de algum modo, facilitam o desenvolvimento da operacionalidade da teoria (CORDEIRO; PEDUZZI, 2013).

Já Krapas (2011) diz que saber dimensionar a complexidade histórica associada à natureza eletromagnética da luz constitui uma grande contribuição (KRAPAS, 2011) para a alfabetização científica.

Conforme mencionado, entender a evolução dos conceitos científicos ajuda o aluno compreender a mutabilidade e a instabilidade da ciência (MATTHEWS, 1995).

\footnotetext{
${ }^{8} \mathrm{OEM}$ - ondas eletromagnéticas.
} 
Em relação aos aspectos da natureza da ciência, procura-se compreender as dificuldades e controvérsias que as comunidades de especialistas enfrentam na elaboração de um modelo (RAMIREZ et al., 2010) com o objetivo de evitar a transmissão de uma imagem positivista da ciência, na qual a sequência de eventos caminha no sentido de atingir um ápice com a proposição de uma lei/conceito (GOMES; PIETROCOLA, 2011). Os artigos dessa revisão evitam propagar, por exemplo, a caricatura genial de Einstein, como se o físico tivesse herdado tais características do berço (URIAS; ASSIS, 2012) porque $o$ estudante que não se considerar tão genial quanto os personagens festejados pelos livros didáticos, se desinteressa em seguir carreira científica ou mesmo, de tentar compreender a ciência (CORDEIRO; PEDUZZI, 2013). A transposição didática da biografia e a auto- biografia dos cientistas deve ser feita com cautela para evitar a "monumentalização", entendida por Alchin (2003) como um artifício para apresentar a genialidade do cientista, valorizando suas conquistas e minimizando seus erros, concedendo ao cientista um status hagiográfico.

Para Cordeiro e Peduzzi (2013), a construção do trabalho empírico precede uma teoria e que propagar a ideia de que a ciência é essencialmente ateórica é danoso, pois intenta conferir ao empreendimento a certeza dos dados fornecidos pela própria natureza (CORDEIRO; PEDUZZI, 2013). Assim, deve-se evitar propagar a concepção empírico-indutivista e ateórica entendida como "uma concepção que destaca o papel "neutro" da observação e da experimentação (não influenciadas por ideias apriorísticas) (GIL PÈREZ et al., 2001)

As propostas de critérios para a avaliação de livros didáticos podem ser baseadas na reconstrução histórica do efeito fotoelétrico (KLASSEN et al., 2012) para se utilizar em manuais de laboratório de curso superior em física; podem admitir a abordagem histórica com aspectos teóricos e matemáticos; clareza e precisão na linguagem; permitir transposição didática; análise crítica de fontes primárias; e considerar o contexto da época (PENA; TEIXEIRA, 2013). Além disso, as propostas de critérios podem mostrar, por exemplo, a criatividade para a formulação de modelos científicos como construção humana (RAMÍREZ et al., 2010). Essas unidades empíricas estão coerentes com outros trabalhos que mostram critérios de análise de conteúdos de livros didáticos impressos de história da ciência direcionados para diversos níveis do ensino presencial tais como em Leite (2002), para o ensino superior presencial; Peters (2005), para o ensino fundamental e Martins (1998), para o ensino médio.

\section{Considerações finais}

Elaboramos seis metatextos com o auxílio da técnica "análise textual discursiva". A leitura desses metatextos possibilita a compreensão das implicações didáticas da história da ciência no ensino de física e pode auxiliar o professor na tomada de decisões sobre qual (is) estratégia (s) de ensino utilizar na sala de aula para conduzir o estudante a compreender a ciência como construção humana e desenvolver a alfabetização científica dos seus alunos. As implicações didáticas no ensino de física envolvem o uso na sala de aula de fontes originais, de 
estudos de caso históricos, de atividades de dramatização, de experimentos históricos, de leitura das biografias e/ou autobiografias dos cientistas e de análise de conteúdo em livros didáticos.

Sobre o uso de fontes originais de história da ciência no ensino de física, percebemos que o contato com as fontes primárias e o contexto em que foram produzidas, ajuda o discente a evitar a visão socialmente neutra da ciência entendida como "uma imagem deformada dos cientistas como seres "acima do bem e do mal", fechados em torres de marfim e alheios à necessidade de fazer opções." (GIL PÈREZ et al., 2001). Além disso, o uso de fontes primárias propiciou um entendimento do discente em relação à transformação dos conteúdos científicos ao longo do tempo evitando assim que o aluno aprenda apenas o paradigma vigente. Outra conclusão obtida junto aos artigos que utilizam a fontes originais é que não existe um consenso sobre os instrumentos de coleta de dados utilizados para mensurar a aprendizagem do aluno em relação à utilização de fontes primárias.

Em relação ao uso de estudo de caso histórico de história da ciência no ensino de física, podemos inferir que ele se revelou eficaz para a compreensão dos conceitos de físicos e entendimento das visões adequadas da natureza da ciência, porque insere o aluno no contexto em que foi produzido o conhecimento. Observamos nos artigos revisados vários comentários dos alunos e dos autores que confirmam esses resultados. Apesar da eficácia dessa estratégia no ensino de física, encontramos em nossa revisão apenas quatro trabalhos envolvendo o estudo de caso.

Por esse motivo existe a necessidade de divulgação dessa estratégia. O grupo de pesquisa em Ensino de Ciências da Universidade Estadual do Norte Fluminense Darcy Ribeiro (UENF) desenvolve um trabalho que envolve a aplicação na sala de aula do estudo de caso histórico com diferentes públicos. Foram construídos, aplicados e publicados, estudos de caso com audiência-alvo da educação de jovens e adultos (HYGINO et al., 2012; 2013).

Sobre o uso de atividades de dramatização de história da ciência no ensino de física, verificamos que a utilização da estratégia de dramatização se mostrou eficiente principalmente para o entendimento dos debates científicos e, para se evitar a propagação da visão socialmente neutra da ciência. Os artigos descrevem que as atividades de dramatização motivam os alunos (SILVERIA et al., 2010) e promovem uma inserção voluntária daqueles alunos que tem dificuldade de entendimento de uma aula tradicional (MEDINA; BRAGA, 2010). A escolha dos textos que serve de alicerce para a construção do roteiro para a encenação, é fundamental para o entendimento dos alunos porque "a maioria das peças que abordam a ciência não é escrita por cientistas, mas por dramaturgos com manifestos conhecimentos em teatro, ao exemplo de Bertolt Brecht (Alemanha) e Osvaldo Mendes (Brasil)" (MEDINA; BRAGA, 2010). Talvez, o professor deva adaptar esses textos para que o mesmo contemple os pormenores da evolução conceitual de uma disciplina e, os aspectos da natureza da ciência.

Em relação ao uso de experimentos históricos de história da ciência no ensino de física, verificamos que a utilização dos experimentos históricos fica mais bem conduzida se estes forem intercalados com leituras de textos históricos para que o aluno compreenda o contexto 
sociocultural da produção dos equipamentos e possam explicar os experimentos à luz dos conceitos da época, evitando assim o anacronismo. A participação intensa dos alunos bem como a motivação deles, foram também aspectos revelados nesses artigos. Alguns obstáculos foram citados pelos discentes como a falta de habilidade manual para construir os equipamentos e a preocupação com os conteúdos da história da ciência que não são cobrados no vestibular.

Sobre o uso de biografias e/ou autobiografia de cientistas no ensino de física, verificamos que essa estratégia de ensino se mostrou promissora para a aplicação da história da ciência na sala de aula, porque coloca o aluno em situações concretas vivenciadas pelos cientistas, porém é preciso ter alguns cuidados em relação a sua utilização porque essas intervenções podem conter elementos que superestima o trabalho do cientista, provocando uma espécie de "endeusamento" do mesmo (CORDEIRO; PEDUZZI, 2010); o que negligenciaria o caráter coletivo da construção do trabalho científico. Talvez, uma maneira de evitar esse erro seria dialogar com outros referenciais teóricos para a compreensão de outros pontos de vistas, culminando assim no pensamento crítico do aluno em relação à vida e a obra dos cientistas. Outro aspecto descrito nos artigos que utilizam biografia e autobiografia na sala de aula foi a constatação da melhoria dos aspectos motivacionais. Isso aconteceu através das falas dos alunos. No entanto, os artigos não apresentam instrumentos para mensurar como a história da ciência motiva a aprendizagem dos estudantes. Talvez seja necessário um diálogo entre a história da ciência e a psicologia cognitiva para compreender melhor esse aspecto.

Sobre a análise da história da ciência em livros didáticos, os artigos proporcionaram uma leitura crítica dos conceitos físicos presentes nos livros didáticos, através da reconstrução histórica desses conceitos e do trabalho dos cientistas. Os autores promovem uma análise de conteúdo desses livros com o objetivo de auxiliar o professor no entendimento de visões adequadas da evolução do conceito científico e da natureza da ciência. Além disso, os autores estabelecem critérios para a avaliação dos conteúdos de história da ciência presentes nos livros didáticos na modalidade do ensino presencial. Não identificamos na nossa revisão critérios para avaliar livros didáticos da educação à distância. Uma proposta de critérios desenvolvida para avaliar materiais didáticos impressos para a educação à distância pode ser visualizada em Rodrigues Junior et al. (2014).

Em relação à metodologia de análise utilizada nesse trabalho, verifica-se que a análise textual discursiva permitiu um diálogo maior entre as unidades empíricas e as unidades teóricas, possibilitando um envolvimento intenso entre o pesquisador e as fontes consultadas.

Os metatextos produzidos neste trabalho constituem leituras independentes e podem auxiliar o professor na escolha das estratégias de ensino adequadas para a sua realidade na sala de aula.

Verificamos nos periódicos analisados a ausência de trabalhos destinados aos alunos da educação à distância. Para minimizar essa lacuna desenvolvemos uma pesquisa de natureza qualitativa na formação continuada de professores de física do Ensino Médio, no qual se buscou 
avaliar uma proposta de história da ciência por meio de um minicurso à distância. Os resultados dessa pesquisa serão apresentados em um trabalho ulterior.

\section{Referências bibliográficas}

ALLCHIN, D. Values in Science: An Educational Perspective. Science \& Education, v. 8, n. 1, p. 1-12, 1999.

Scientific myth-conceptions. Science Education, v. 87, n. 3, p. 329-351, 2003.

BLOWN, E. J.; BRYCE, T. G. Thought-experiments about gravity in the History of Science and in research into children's thinking. Science \& Education, v. 22, n. 3, p. 419-481, 2013.

BORGES, R. M. Em debate: Cientificidade e Educação em Ciências. Porto Alegre: SE/CECIRS, 1996. 75p.

BORGES, O. Formação inicial de professores de física: Formar mais! Formar melhor! Revista Brasileira de ensino de Física, v.28 n. 2, p. 135-142, 2006.

BRAGA, M.; GUERRA, A.; REIS, J. C. Breve história da Ciência Moderna. 1. ed. Rio de Janeiro: Jorge Zahar, 2004. v. 1, 2, 3 e 4.

BRAGA, M.; GUERRA, A.; REIS, J. C. The Role of Historical-Philosophical controversies in teaching sciences: the debate between Biot and Ampère. Science \& Education, v. 21, n. 6, p. 921-934, 2012.

BRASIL. Diretrizes Curriculares Nacionais para a Formação de Professores da Educação Básica. Parecer CNE/CP 9/2001. Disponível em: <http://portal.mec.gov.br/cne/arquivos/pdf/009.pdf>. Acesso em: 02 set. 2013.

BRASIL. Ministério da Educação. Orientações Educacionais Complementares aos Parâmetros Curriculares Nacionais. Ciências da Natureza, Matemática e suas Tecnologias. Brasília: MEC, 2002. Disponível em: <http://portal.mec.gov.br/seb/arquivos/pdf/CienciasNatureza.pdf>. Acesso em: 05 set. 2013.

BRASIL. Ministério da Educação. Secretaria de Educação Fundamental. Parâmetros Curriculares Nacionais. $3^{\circ}$ e $4^{\circ}$ ciclos do ensino fundamental. Brasília: MEC, 1998. Disponível em: <http://portal.mec.gov.br/seb/arquivos/pdf/introducao.pdf >. Acesso em: 05 jul. 2014.

BRASIL. Ministério da Educação. Secretaria de Educação Média e Tecnológica. Parâmetros Curriculares Nacionais: Ensino Médio. Parte III- Ciências da Natureza, Matemática e suas Tecnologias. Brasília, MEC, 2000. Disponível em: <http://portal.mec.gov.br/seb/arquivos/pdf/ciencian.pdf $>$. Acesso em: 02 set.2013. 
BRUSH, Stephen G. History of Science and Science Education. Interchange, v. 20, n. 2, p.6070, 1989.

BRENNI, P. The evolution of teaching instruments and their use between 1800 and 1930. Science \& Education, v. 21, n. 2, p. 191-226, 2012.

BRICCIA, V.; CARVALHO, A. M. P. Visões sobre a natureza da ciência construídas a partir do uso de um texto histórico na escola média. Revista Eletrónica de Enseñanza de las Ciencias, v. 10, n. 1, p. 1-22, 2011.

CHALMERS, A. F. O que é ciência Afinal? São Paulo: Brasiliense, 1993. 224 p.

COELHO, R. L. On the concept of force: how understanding its history can improve Physics Teaching. Science \& Education, v. 19, n. 1, p. 91-113, 2010.

CORDEIRO, M. D.; PEDUZZI, L. O. As conferências Nobel de Marie e Pierre Curie: A gênese da radioatividade no ensino. Caderno Brasileiro de Ensino de Física, v. 27, n. 3, p. 473-514, 2010.

Aspectos da natureza da ciência e do trabalho científico no período inicial de desenvolvimento da radioatividade. Revista Brasileira de Ensino de Física, v. 33, n. 3, p. 3601, 2011.

Consequências das descontextualizações em um livro didático: uma análise do tema radioatividade. Revista Brasileira de Ensino de Física, v. 35, n. 3, p. 3602, 2013.

DUARTE, M. A História da Ciência na prática de professores portugueses: implicação para a formação de professores de ciências. Ciência \& Educação, v. 10, n. 3, p. 317-331, 2004.

DUCHEYNE, S. The Cavendish experiment as a tool for historical understanding of science. Science \& Education, v. 21, n. 1, p. 87-108, 2012.

EL-HANI, C. Notas sobre o ensino de história e filosofia da ciência na educação científica de nível superior. In: SILVA, C. C. (Org.). Estudos de História e Filosofia das Ciências: subsídios para aplicação no Ensino. São Paulo, SP: Livraria da Física, 2006. cap.1, p. 3-21.

FERREIRA, J. M. Abordando a natureza da ciência na formação de professores de física: desafios e perspectivas. In: SILVA, C. C.; PRESTES, M. E. (Orgs.). Aprendendo ciência e sobre sua natureza: abordagens históricas e filosóficas. 1. ed. São Carlos, SP: Tipografia Editora, 2013. cap. 3, p. 251-263.

FERREIRA, C.; MEIRELLES, R. O ensino de ciências nas diretrizes curriculares nacionais para a formação de professores da Educação Básica no Brasil: um estudo preliminar. Disponível em: <http://www.nutes.ufrj.br/abrapec/viiienpec/resumos/R0932-1.pdf>. Acesso em: 20 abr. 2013. 
FERREIRA, J. M.; MARTINS, A. M. A história e a filosofia da ciência no ensino de ciências. Aula 2, 2008. Disponível em: <http://www.4shared.com/office/8O-oiEVyce/hfc_a02_no_ensino_de_ciencias.html?>. Acesso em: 12 jul. 2014.

FLECK, L. La gênesis y el desarrollo de un hecho científico. Madrid: Alianza Editorial, 1986. $98 \mathrm{p}$.

FORATO, T. C.; PIETROCOLA, M.; MARTINS, R. A. Historiografia e natureza da ciência na sala de aula. Caderno Brasileiro de Ensino de Física, v. 28, n. 1, p. 27-59, abr. 2011.

FORATO, T. C. A natureza da ciência como saber escolar: um estudo de caso a partir da natureza da luz. 2009. 420f. Tese (Doutorado em Educação) - Faculdade de Educação, USP, São Paulo.

FRANCISQUINI, M. F.; SOARES, V,; TORT, A. C. O paradoxo cinemático de Galileu. Revista Brasileira de Ensino de Física, v. 36, n. 1, p. 1304, 2014.

GAULD, C. F. Newton's investigation of the resistance to moving bodies in continuous fluids and the nature of "Frontier Science". Science \& Education, v. 19, n. 10, p. 939-961, 2010.

GIL PÉREZ, D. et al. Para uma imagem não deformada do trabalho científico. Ciência \& Educação, v. 7, n. 2, p. 125-153, 2001.

GOMES, G. G.; PIETROCOLA, M. O experimento de Stern-Gerlach e o spin do elétron: um exemplo de quasi-história. Revista Brasileira de Ensino de Física, v. 33, n. 2, p. 2604, 2011.

GOMES, L. C. A ascensão e queda da teoria do Calórico, Caderno Brasileiro de Ensino de Física, v. 29, n. 3, p. 1030-1073, 2012.

GRAVROGLU, K. O Passado das Ciências como História. 1. ed. Lisboa: Porto editora, 2007. $301 \mathrm{p}$.

GUERRA, A.; BRAGA, M.; REIS, J. C. History, Philosophy, and Science in a social perspective: a pedagogical project. Science \& Education, v. 22, n. 6, p. 1485-1503, 2013.

GUERRA, A.; REIS, J. C.; BRAGA, M. Tempo, espaço e simultaneidade: Uma questão para os cientistas, artistas, engenheiros e matemáticos no Século XIX. Caderno Brasileiro de Ensino de Física, v. 27, n. 3, p. 568-583, 2010.

HYGINO, C. B.; MARCELINO, V. S.; LINHARES, M. P. Modelos didáticos presentes na formação de futuros professores de química e física da região norte do estado do Rio de Janeiro, Brasil: encontros e desencontros entre concepções e formação. Revista Electrónica de Investigación en Educación en Ciencias, v. 8, n. 2, p. 49-58, 2013. 
HYGINO, C. B.; SOUZA, N. S.; LINHARES, M. P. Episódios da história da ciência e aulas de física com alunos jovens e adultos: uma proposta didática articulada ao método de estudo de caso. Revista Eletrónica de Enseñanza de las Ciencias, v. 12, n. 1, p. 1-23, 2013.

HYGINO, C. B.; SOUZA, N. S. Reflexões sobre a natureza da ciência em aulas de física: Estudo de um episódio histórico do Brasil colonial. Experiências em ensino de Ciências, v. 7, n. 2, p. 14-24, 2012.

IERVOLINO, S. A.; PELICIONE, M. C. A utilização do grupo focal como metodologia qualitativa na promoção da saúde. Revista da Escola da Enfermagem da USP, São Paulo, v. 35, n. 2, p. 115-21, 2001.

JUNIOR, L. A.; CUNHA, M. F.; LARANJEIRAS, C. C. Simulação de experimentos históricos no ensino de física: uma abordagem computacional das dimensões históricas e empírica da ciência na sala de aula. Revista Brasileira de Ensino de Física, v. 34, n. 4, p. 4602, 2012.

KLASSEN, S.; NIAZ, D.; METZ, D.; MCMILLAN, B. Portrayal of the history of the photoelectric effect in laboratory instructions. Science \& Education, v. 21, n. 5, p. 729-743, 2012.

The photoelectric effect: reconstructing the story for the Physics classroom. Science \& Education, v. 20, n. 7, p. 719-731, 2010.

KRAPAS, S. Livros didáticos: Maxwell e a transposição didática da luz como onda eletromagnética. Caderno Brasileiro de Ensino de Física, v. 28, n. 3, p. 564-600, 2011.

LEDERMAN, N. et al. Views of nature of science questionnaire: towards valid and meaningful assessment of learners' conceptions of the nature of science. Journal of Research in Science Teaching, v. 39 n. 6, p.497-521, 2002.

LEITE, L. History of Science in Educacion: development and validation of a checklist for analysing the historical content of science textbooks. Science \& Education, v. 11, n. 4, p. 333 $359,2002$.

LUDKE, M.; ANDRÉ, M. Pesquisa em educação: abordagens qualitativas. São Paulo: EPU, 1996. 99 p.

MARTINS, A. F. P. História e Filosofia da Ciência no ensino: há muitas pedras nesse caminho... Caderno Brasileiro de Ensino de Física, v. 24, n. 1, p. 112-131, 2007.

RYDER, J. Há realmente um consenso acerca da natureza da ciência no ensino de ciências? In: ENCONTRO NACIONAL DE PESQUISA EM ENSINO DE FÍSICA, XV, 2014, Maresias. Atas... Disponível em: < http://www.sbf1.sbfisica.org.br/eventos/epef/xv/sys/resumos/T0135-1.pdf>. Acesso em: 13 out. 2015. 
MARTINS, L. A. A História da Ciência e o ensino de Biologia. Ciência \& Ensino, n. 5, p. 18$21,1998$.

MATTHEWS, M. Changing the focus: from nature of science to features of science. Disponível em: <http://www.bu.edu/hps-scied/files/2012/10/Matthews-HPS-Changing-the-Focus-FromNature-of-Science-to-Features-of-Science.pdf>. Acesso em: 13 out. 2015.

História e Filosofia da Ciência: a tendência atual de reaproximação. Caderno Catarinense de Ensino de Física, v. 12, n. 3, p. 164-214, 1995.

MCCOMAS, W. Uma proposta de classificação para os tipos de aplicação da história da ciência na formação científica: implicações para a pesquisa e desenvolvimento. In: SILVA, C.C.; PRESTES, M. E. (Orgs.). Aprendendo ciência e sobre sua natureza: abordagens históricas e filosóficas. 1. ed. São Carlos, SP: Tipografia Editora, 2013. cap. 4, p. 425-448.

MEDINA, M.; BRAGA, M. O teatro como ferramenta de aprendizagem da física e de problematização da natureza da ciência, Caderno Brasileiro de Ensino de Física, v. 27, n. 2, p. 313 $333,2010$.

METZ, D.; KLASSEN, S.; MCMILLAN, B.; CLOUGH, M.; OLSON, J. Building a Foundation for the use of historical Narratives. Science \& Education, v. 16, n. 3, p. 313-334, 2007.

MORAES, R.; GALIAZZI, M. C. Análise textual discursiva. Ijuí: Unijuí, 2011. 224 p.

MORAIS, A.; GUERRA. A. História e a filosofia da ciência: caminhos para a inserção de temas física moderna no estudo de energia na primeira série do Ensino Médio. Revista Brasileira de Ensino de Física, v. 35, n. 1, p. 1502, 2013.

NARASIMHAN, M. G. Controversy in science. Journal of Biosciences, v. 26, n. 3, p. 299304, 2001.

NETO, C. P.; JUNIOR, O. F. Herch Moyses Nussenzveig e a ótica quântica: consolidando disciplinas através de escolas de verão e livros-texto. Revista Brasileira de Ensino de Física, v. 35, n. $2,2013$.

NÓBREGA, M. L; JR, O. F; PINHO, S. T. Max Planck e os enunciados da segunda lei da termodinâmica. Revista Brasileira de Ensino de Física, v. 35, n. 2, p. 3601, 2013.

OLIVEIRA, C. E.; FIREMAN, E. C.; FILHO, J. B. A solução atribuída a D’Alembert sobre a 'Verdadeira Força' é capaz de diminuir a polêmica ensejada pela crítica de Leibniz a Descartes? Investigações em Ensino de Ciências, v. 18, n. 3, p. 581-600, 2013.

PARASKEVOPOULOU, E.; KOLIOPOULOS, D. Teaching the Nature of Science through the Millikan-Ehrenhaft dispute. Science \& Education, v. 20, n. 10, p. 943-960, 2011. 
PEDUZZI, L. O. Evolução dos conceitos da Física. Florianopolis: UFSC/EAD/CED/CFM, 2011. 129p.

Física Aristotélica: por que não considerá-la no ensino da mecânica? Caderno Catarinense de Ensino de Física, v. 13, n. 1, p. 48-63, 1996.

PENA, F. L.; TEIXEIRA, E. S. Parâmetros para avaliar a produção literária em história e filosofia da ciência voltada para o ensino e divulgação das ideias da física. Caderno Brasileiro de Ensino de Física, v. 30, n. 3, p. 471-491, 2013.

PENEIRO, J. C. Algumas considerações de Galileo a respeito das teorias da semelhança física, da resistência dos materiais e das flexões. Caderno Brasileiro de Ensino de Física, v. 27, n. 2, p. 288-312, 2010.

PETERS, J. R. A história da Matemática no Ensino Fundamental: uma análise de livros didáticos e artigos sobre história. 2005. 170 f. Dissertação (Mestrado em Educação Científica e Tecnológica) - UFSC, Florianópolis.

PILIOURAS, P; SIAKAS, S.; SEROGLOU, F. Pupils produce their own narratives inspired by the History of Science: animation movies concerning the geocentric-heliocentric debate. Science \& Education, v. 20, n. 7, p. 761-795, 2011.

PNLD - Guia do Programa Nacional do Livro Didático (PNLD-2011-EJA). Disponível em: $<$ http://www.fnde.gov.br/programas/livro-didatico/guia-do-livro/item/512-guia-pnld-2011educa\%C3\%A7\%C3\%A3o-de-jovens-e-adultos>. Acesso em: 02 ago. 2013.

PNLD - Guia do Programa Nacional do Livro Didático (PNLD-2012-Física). Disponível em: <http://www.fnde.gov.br/programas/livro-didatico/guia-do-livro/item/2988-guia-pnld2012-ensino-m\%C3\%A9dio>. Acesso em: 02 ago. 2013.

PORTO, F. S.; ZIMMERMANN, E.; HARTMAM, A. M. Exposições museológicas para aprendizagem de física em espaços formais de educação: um estudo de caso. Caderno Brasileiro de Ensino de Física, v. 27, n. 1, p. 26-62, 2010.

PRESTES, M. E; CALDEIRA, A. M. Introdução. A importância da história da ciência na educação científica. Filosofia e História da Biologia, 2009. v. 4, p. 1-16.

RAMÍREZ, J. E.; BADILLO, R.G.; MIRANDA, R. P. El modelo semicuántico de Bohr en los libros de texto. Ciência \& Educação, v. 16, n. 3, p. 611-629, 2010.

REIS, E. M.; LINHARES, M. P. Ambientes virtuais de aprendizagem no Ensino de ciências no Proeja. In: SIMPÓSIO NACIONAL DE ENSINO DE FÍSICA, XIX, 2011, Manaus. Atas... 
REIS, V. Jonh Ziman - Físico e epistemólogo em uma "ciência pós-acadêmica". In: HAYSAHI, M. C; RIGOLIN, C.C; KERBAUY, M. T (Orgs.). Sociologia da Ciência: contribuições ao campo CTS. Campinas: Editora Alínea, 2014. cap. 9, p. 211-238.

RINALDI, E.; GUERRA, A. História da ciência e o uso da instrumentação: construção de um transmissor de voz como estratégia de ensino. Caderno Brasileiro de Ensino de Física, v. 28, n. 3, p. 653-675, 2011.

RODRIGUES, E. V.; ZIMMERMANN, E.; HARTMAM, A. M. Lei da Gravitação universal e os satélites: uma abordagem histórico-temática usando multimídia. Ciência \& Educação, v. 18, n. 3, p. 503-525, 2012.

RODRIGUES JUNIOR, E. et al. Critérios para a avaliação de materiais didáticos impressos para a educação à distância. Caderno Brasileiro de Ensino de Física, v. 31, n. 1, 2014.

SASSERRON, L.; BRICCIA, V.; CARVALHO, A. Aspectos da natureza da ciência em sala de aula: exemplos do uso de textos científicos em prol do processo de alfabetização científica dos estudantes In: SILVA, C. C.; PRESTES, M. E (Orgs.). Aprendendo ciência e sobre sua natureza: abordagens históricas e filosóficas. 1. ed. São Carlos: Tipografia Editora, 2013. cap. 3, p. 265-276.

SEKER, H.; GUNEY, B. G. History of Science in the Physics curriculum: a directed content analysis of historical sources. Science \& Education, v. 21, n. 5, p. 683-703, 2012.

SEQUEIRA, M; LEITE, L. A História da Ciência no ensino-aprendizagem das ciências. Revista Portuguesa de Educação, v. 30, n. 2, p. 29-40, 1988.

SILVA, B. V; MARTINS, A. F. A Natureza da luz e o ensino da óptica: uma experiência didática envolvendo o uso da história e da filosofia da ciência no ensino médio. Experiências em ensino de Ciências, v. 5, n. 2, p. 71-91, 2010.

SILVA, C. P.; FREIRE J. O. Herch Moysés Nussenzveig e a ótica quântica: consolidando disciplinas através de escolas de verão e livros-texto. Revista Brasileira de Ensino de Física, v. 35, n. 2, p. 2601, 2013.

SILVA, C. C.; PRESTES, M. E. (Orgs.). Aprendendo ciência e sobre sua natureza: abordagens históricas e filosóficas. 1. ed. São Carlos: Tipografia Editora, 2013.

SILVA, L. C.; SANTOS, W. M.; DIAS, P. M. A carga específica do elétron: um enfoque histórico e experimental. Revista Brasileira de Ensino de Física, v. 33, n. 1, p. 1601, 2011.

SILVEIRA, A. F. et al. Natureza da Ciência numa sequência didática: Aristóteles, Galileu e o Movimento Relativo. Experiências em ensino de Ciências, v. 5, n. 1, p. 57-66, 2010. 
SILVEIRA, F.; OESTERMANN, F. A. A insustentabilidade da proposta indutivista de "descobrir a lei a partir de resultados experimentais”. Caderno Brasileiro de Ensino de Física, v. 19, número especial, p. 7-27, 2002.

STINNER, A. et al. The renewal of case studies in Science Education. Science \& Education, v. 12, n. 7, p. 617-643, 2003.

TEIXEIRA, E. S.; PEDUZZI, L. O; JUNIOR, O. F. Os caminhos de Newton para a gravitação universal: uma revisão do debate historiográfico entre Cohen e Westfall. Caderno Brasileiro de Ensino de Física, v. 27, n. 2, p. 215-254, 2010.

URIAS, G.; ASSIS, A. Análise de biografias de Einstein em dois livros de divulgação científica. Caderno Brasileiro de Ensino de Física, v. 29, n. 2, p. 207-228, 2012.

ZANETIC, J. Física também é cultura. 1989. 252 f. Tese (Doutorado em Educação) Faculdade de Educação, USP, São Paulo.

ZANOTELLO, M. Leitura e textos originais de cientistas por estudantes do ensino superior. Ciência \& Educação, v. 17, n. 4, p. 987-1013, 2011.

ZÔMPERO, A. F.; LABURÚ, C. E. Atividades investigativas no ensino de ciências: aspectos históricos e diferentes abordagens. Revista Ensaio, v. 13, n. 3, p. 67-80, 2011. 